\title{
Fire behavior of lead-containing PMMA based Kyowaglas
}

\author{
H. Mastori ${ }^{\mathrm{a}, *}$, R. Sonnier ${ }^{\mathrm{b}}$, L. Ferry ${ }^{\mathrm{b}}$, M. Coutin $^{\mathrm{a}}$ \\ a Institut de Radioprotection et de Sûreté Nucléaire (IRSN), PSN-RES/SA2I, Cadarache, Saint-Paul-Lez-Durance 13115, France \\ ${ }^{\mathrm{b}}$ IMT - Mines Ales, Polymers Hybrids and Composites (PCH), 6 Avenue De Clavières, Alès Cedex F-30319, France
}

\begin{abstract}
A B S T R A C T
In the present work, the flammability of Kyowaglas is characterized experimentally. Kyowaglas is a leadbased composite used in glove boxes of nuclear facilities as a biological protection against radiation. It consists of $70 \%$ wt PMMA (Poly(Methyl Methacrylate)) and 30\% $\%_{w t}$ leaded compounds. The aim of the study is to understand the role and impact of lead during the combustion of Kyowaglas in order to deepen knowledge of its thermal and fire behavior. A comparative study between Kyowaglas and virgin PMMA is conducted to better understand the effect of lead on the combustion process of these materials. Fire behavior is studied using cone calorimeter, pyrolysis-combustion flow calorimeter and thermogravimetric analysis. At different stages of cone calorimeter test, the samples and residues were examined and characterized using different experimental techniques like microscopy, spectroscopy, X-ray diffraction and calorimetry. Thermal analysis data show that lead seems to slightly accelerate the decomposition of PMMA under inert atmosphere. However, it confers significant thermal stability during a cone test due to the accumulation of lead on the surface of the sample. As the Kyowaglas burns, metallic lead is formed and accumulated at the top surface slowing down the heat transfer. At the end of the cone calorimeter test, lead oxide beads start to form on the surface of the residue due to the oxidation of metallic lead.
\end{abstract}

Keywords:

Kyowaglas

PMMA

Lead

Lead oxide

Thermal stability

\section{Introduction}

In nuclear facilities such as fuel treatment or waste reprocessing plants, the first level of containment of nuclear materials is generally the glove box. A glove box consists of a steel frame and panels of polymeric material, in most cases Polycarbonate (PC), 10 $\mathrm{mm}$ thick, and/or stainless steel sheets, $2 \mathrm{~mm}$ thick, with glove holes for handling of radioactive material. This box constitutes a closed volume and is kept in depression, in order to avoid any leakage of radioactive material. Depending on nature of elements contained in the glove box, an additional biological protection panel can be added to the outer wall, providing biological shielding to protect the operator from radiation exposures. These panels are of-

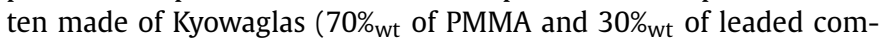
pounds of unknown nature) with a thickness of $50 \mathrm{~mm} \mathrm{[1].}$

Accidental fires in nuclear facilities can cause containments of glove boxes to rupture with a dispersion of radioactive elements in the facility and the environment. Thus, for many years, industrialists and research organizations involved in nuclear industry have been working on fire-related issues, in order to strengthen

\footnotetext{
* Corresponding author.

E-mail address: helena.mastori@irsn.fr (H. Mastori).
}

the means of prevention by a better understanding of the involved phenomena.

Despite the widespread use of Kyowaglas in nuclear industry, few results are available, describing its overall fire behavior. This material has some drawbacks, which limit its use such as its high cost, heaviness, low mechanical and chemical stability and above all its high toxicity [2]. The study of the fire behavior of Kyowaglas is therefore fundamental to better assess the hazard resulting from a glove box fire.

The present study is part of a research program called FIGARO (Fires Involving Glove boxes with Aerosol Release Occurrences), conducted by the Institut de Radioprotection et de Sûreté Nucléaire (IRSN), on the characterization of glove box fires and the suspension of radionuclides involved in these scenarios. This program allows a more realistic estimate of the quantity of radioactive material involved in a glove box fire scenario and likely to be released to the environment. As part of the FIGARO project, and for health reasons, carrying out fire tests on glove boxes fitted with Kyowaglas panels would be dangerous due to the toxic nature of lead compounds contained in these panels. Therefore, it is necessary to identify a non-toxic surrogate material whose fire behavior is as close as possible to that of Kyowaglas in order to carry out fire tests on glove boxes representative of those of nuclear facilities. To do this, it will first be important to characterize the Kyowaglas in 


\section{Nomenclature (international system of units)}

\%Residue residue yield - cone calorimeter (\%)

\%Residue PCFC residue yield - PCFC (\%)

A sample area $\left(\mathrm{m}^{2}\right)$

CHF critical heat flux $\left(\mathrm{W} / \mathrm{m}^{2}\right)$

Cp specific heat $(\mathrm{J} / \mathrm{kg} . \mathrm{K})$

DTG differential thermogravimetry $(\% / \mathrm{s})$

E thermal effusivity (W. $\mathrm{s}^{0.5} / \mathrm{m}^{2} . \mathrm{K}$ )

EHC effective heat of combustion - cone calorimeter $(\mathrm{J} / \mathrm{kg})$

EHC $_{\text {PCFC }}$ effective heat of combustion - PCFC $(\mathrm{J} / \mathrm{kg})$

hc convective heat transfer coefficient $\left(\mathrm{W} / \mathrm{m}^{2} . \mathrm{K}\right)$

$\mathrm{h}_{\mathrm{R}} \quad$ radiation approximation coefficient $\left(\mathrm{W} / \mathrm{m}^{2} . \mathrm{K}\right)$

HRR heat release rate - cone calorimeter $\left(\mathrm{W} / \mathrm{m}^{2}\right)$

HRR $_{\text {PCFC }}$ heat release rate - PCFC $(\mathrm{W} / \mathrm{kg})$

$\mathrm{k}$ thermal conductivity (W/m.K)

ML mass loss (\%)

MLR mass loss rate $(\mathrm{kg} / \mathrm{s})$

$\mathrm{Pb} \quad$ lead

$\mathrm{PbO} \quad$ lead oxide

PC poly carbonate

pHRR peak of HRR - cone calorimeter $\left(\mathrm{W} / \mathrm{m}^{2}\right)$

pHRR $_{\text {PCFC }}$ peak of HRR - PCFC $(\mathrm{W} / \mathrm{kg})$

$\dot{\mathrm{q}}_{\mathrm{e}}^{\prime \prime} \quad$ external heat flux $\left(\mathrm{W} / \mathrm{m}^{2}\right)$

$\dot{\mathrm{q}}_{\mathrm{fl}}^{\prime \prime} \quad$ heat flux from the flame $\left(\mathrm{W} / \mathrm{m}^{2}\right)$

$\mathrm{r}$ surface reflectivity

RSR smoke release rate $\left(\left(\mathrm{m}^{2} / \mathrm{s}\right) / \mathrm{m}^{2}\right)$

SMLR specific mass loss rate $\left(\mathrm{kg} / \mathrm{m}^{2} . \mathrm{s}\right)$

$\overline{\text { SMLR }}$ averaged specific mass loss rate $\left(\mathrm{kg} / \mathrm{m}^{2} . \mathrm{s}\right)$

SPR smoke production rate $\left(\mathrm{m}^{2} / \mathrm{s}\right)$

$\mathrm{T}$ temperature $\left({ }^{\circ} \mathrm{C}\right)$

t time (s)

$\mathrm{t}$ pHRR time to pHRR (s)

$\mathrm{T}_{0} \quad$ ambient temperature $\left({ }^{\circ} \mathrm{C}\right)$

$\mathrm{T}_{10} \quad$ temperature at which $10 \%$ weight loss occurs - ATG $\left({ }^{\circ} \mathrm{C}\right)$

$\mathrm{T}_{50} \quad$ temperature at which $50 \%$ weight loss occurs - ATG $\left({ }^{\circ} \mathrm{C}\right)$

TG thermogravimetry (\%)

THR total heat release - cone calorimeter $\left(\mathrm{J} / \mathrm{m}^{2}\right)$

THR $_{\text {PCFC }}$ total heat release - PCFC $(\mathrm{J} / \mathrm{kg})$

$\mathrm{T}_{\mathrm{ig}} \quad$ ignition temperature $\left({ }^{\circ} \mathrm{C}\right)$

TOF time of flameout (s)

$\mathrm{T}_{\text {pHRR-PCFC }}$ temperature at pHRR $-\operatorname{PCFC}\left({ }^{\circ} \mathrm{C}\right)$

$\mathrm{T}_{\mathrm{S}} \quad$ surface temperature $\left({ }^{\circ} \mathrm{C}\right)$

TSR total smoke release $\left(\mathrm{m}^{2} / \mathrm{m}^{2} \cdot \mathrm{kg}\right)$

TTI TIME TO IGNITIon (s)

$\mathrm{x} \quad$ in-depth distance $(\mathrm{m})$

Greek characters

$\alpha \quad$ thermal diffusivity $\left(\mathrm{m}^{2} / \mathrm{s}\right)$

$\beta_{\mathrm{a}} \quad$ ratio of the non-reflected heat flux to the in-depth

$\beta_{\mathrm{L}} \quad$ ratio of the convective and radiative heat losses

from the surface to the environment

$\delta \quad$ depth of thermal penetration (m)

$\Delta \mathrm{G} \quad$ Gibbs Free Energy (J)

$\Delta \mathrm{Hg} \quad$ latent heat of gasification $(\mathrm{J} / \mathrm{kg})$

$\varepsilon \quad$ surface emissivity (1- reflectivity $\mathrm{r}$ )

$\kappa \quad$ absorption coefficient $\left(\mathrm{m}^{-1}\right)$

$\rho \quad$ density $\left(\mathrm{kg} / \mathrm{m}^{3}\right)$

$\sigma \quad$ Stephan-Boltzmann constant $\left(\mathrm{W} / \mathrm{m}^{2} \cdot \mathrm{K}^{4}\right)$

$\theta \quad$ temperature rise $\left(\mathrm{T}-\mathrm{T}_{0}\right)\left({ }^{\circ} \mathrm{C}\right)$ order to deepen knowledge of its thermal behavior. Hence, Kyowaglas characterization is the purpose of the present paper.

Hence, in this study the thermo-physical properties of Kyowaglas, namely specific heat capacity, density and thermal diffusivity, are estimated using Differential Scanning Calorimetry (DSC), Helium pycnometry and Xenon Flash Apparatus (XFA), respectively. The fire behavior of Kyowaglas is assessed at microscale using Pyrolysis Combustion Flow Calorimetry (PCFC) and Thermogravimetric Analysis (TGA) and at bench scale using a cone calorimeter at various heat fluxes. A specific emphasis is paid on lead species during burning in order to understand what happens to lead and how it influences the flammability. For this purpose, the microstructure as well as the elementary composition of this material, at different stages, are characterized using Scanning Electron Microscopy (SEM) and Energy-dispersive X-ray Spectroscopy (EDXS). For comparison purpose, the same tests were carried out on pure PMMA.

\section{Experimental description}

\subsection{Materials}

Kyowaglas sheets supplied by KYOWAGLAS-XA®, Kuraray (Tokyo, Japan) are used in this study. Clear PMMA V825T was supplied by ALTUGLAS® International.

\subsection{Experimental techniques}

\subsubsection{Differential scanning calorimetry (DSC)}

DSC is a technique that measures the heat flux absorbed or given off by a specimen as a function of temperature or time when it is subjected to a temperature program in a controlled atmosphere. The DSC device comprises two micro-furnaces on which crucibles are placed, the first corresponding to the sample and the second to the reference. The two crucibles are of the same composition, thermally decoupled and maintained at a constant and identical temperature. Each of the micro-furnaces is equipped with a temperature sensor and a heat resistance. The principle of this device is that at all times, the temperatures of the two microfurnaces are kept identical. When a thermal phenomenon takes place in the specimen, the device reacts to restore temperature equality. The resulting difference in the heat exchanged between the crucibles and the micro-furnaces is recorded in the form of a thermogram. In this study, the specific heat (Cp) is measured using a PerkinElmer DSC apparatus over the temperature range $-20^{\circ} \mathrm{C}$ to $40^{\circ} \mathrm{C}, \pm 0.1^{\circ} \mathrm{C}$, at a heating rate of $2^{\circ} \mathrm{C} / \mathrm{min}$. The tested samples are in the form of grains. Their weight is in the range $8-10 \mathrm{mg}$. All DSC measurements are done in duplicate, and the results are averaged.

\subsubsection{Xenon flash apparatus (XFA)}

Thermal diffusivity $(\alpha)$ was measured using a Xenon Flash Apparatus from Linseis under nitrogen at ambient temperature. XFA apparatus is similar to Laser Flash apparatus but the light source that is used is Xenon instead of Laser. To measure thermal diffusivity, the sample is placed on a sample holder located in the center of a furnace. The temperature is set and the furnace stabilizes at the set temperature. The lower part of the sample is irradiated with a programmed energy pulse (Xenon-Flash lamp). The pulse results in a homogeneous rise in temperature within the sample. This temperature rise is measured on the upper side of the sample using a high speed infrared detector. Thereafter, thermal diffusivity is calculated from the temperature versus time curve with an accuracy of $\pm 2.4 \%$. The samples tested are in the form of a circular pellet $2 \mathrm{~cm}$ in diameter and $2 \mathrm{~mm}$ thick. All XFA measurements are repeated four times, and the results are averaged. Knowing the 
values of the density and the specific heat of the material, thermal conductivity ( $\mathrm{k}$ ) was then calculated using Eq. (1):

$k \approx C p . \alpha . \rho$

where $\mathrm{k}$ is the thermal conductivity $(\mathrm{W} / \mathrm{m} . \mathrm{K}), \alpha$ is the thermal diffusivity $\left(\mathrm{m}^{2} / \mathrm{s}\right), \mathrm{Cp}$ is the specific heat $(\mathrm{J} / \mathrm{kg} . \mathrm{K})$ and $\rho$ is the density $\left(\mathrm{kg} / \mathrm{m}^{3}\right)$.

\subsubsection{Helium pycnometry}

Helium pycnometry tests were carried out on Micromeritics AcсиPус 1330 gas pycnometer to determine the density. This device makes it possible to measure the density of a sample. It has two chambers whose volumes are known. The sample is placed in the first chamber in which inert gas, helium, is admitted at known ambient pressure and temperature. The second chamber, called the expansion chamber, is also in a helium atmosphere, at known ambient pressure and temperature. After opening the valve connecting the two chambers, the helium contained in the first chamber expands to occupy all of the available volume. In accordance with the ideal gas law, measuring the pressure before and after opening the valve allows the actual volume of a sample to be deduced. When a sample weight is specified, the density is derived automatically with an accuracy of $\pm 0.01 \%$. The weight of the samples which are in the form of grains is in the range 5-8 mg. All density measurements are done in duplicate, and the results are averaged.

\subsubsection{Thermo-gravimetric analysis (TGA)}

TGA is an adapted technique for studying the mass variation of samples submitted to temperature stress. A TGA apparatus typically consists of a sealed enclosure with controlled atmosphere, a furnace and a thermocouple for measuring the temperature, a microbalance and a computer in order to control the measurement and to record the data. TGA experiments were performed under nitrogen using a Setaram Instrumentation apparatus. Temperature ranges from room temperature up to $900{ }^{\circ} \mathrm{C}$ at a rate of $10^{\circ} \mathrm{C} / \mathrm{min}$. The weight of the samples is in the range $8-10 \mathrm{mg}$. TGA measurements are done in duplicate for each material. Good repeatability is observed between the different tests.

\subsubsection{Pyrolysis combustion flow calorimetry (PCFC)}

PCFC developed by Lyon and Walters [3,4] allows quantifying the heat release at microscale with only a few milligrams of material. The PCFC is a combustion microcalorimeter that measures the combustibility of a small amount of sample. This device is made up of two chambers: a so-called pyrolysis chamber (pyrolyzer) in which the material is thermally degraded and a post combustion chamber (combustor) in which the combustion effluents are conveyed and undergo oxidative combustion. The thermal degradation of the sample takes place under an inert atmosphere (anaerobic condition). In some cases, one can work in an oxidizing atmosphere (aerobic condition) from $25^{\circ} \mathrm{C}$ to $750^{\circ} \mathrm{C}$. The combustion gases produced are then directed into the second combustion chamber where their oxidation takes place at $900^{\circ} \mathrm{C}$. An oxygen analyzer measures the amount of oxygen consumed to determine the heat of combustion of thermal degradation products. Indeed, according to the principle of Huggett which stipulates that the heat of combustion of an organic material is directly related to the quantity of oxygen necessary for its combustion, one can determine the heat release rate (HRR) (W/g), peak of HRR (pHRR), Total Heat Release (THR) and Effective Heat of Combustion (EHC). In this study, all the measurements with the PCFC analyses were carried out using a FAA micro-calorimeter from Fire Testing Technology (UK) in standard conditions, i.e. anaerobic pyrolysis (method A from ASTM standard D 7309 [5]) from 100 to $750^{\circ} \mathrm{C}$ at $1^{\circ} \mathrm{C} / \mathrm{s}$ and combustion at $900^{\circ} \mathrm{C}$ in excess of oxygen. Some tests were also performed on virgin material or residue previously obtained from anaerobic pyrolysis according to method B (aerobic pyrolysis) with an oxygen fraction of $20 \%$ in the pyrolysis chamber. The mass of the sample was about $10.00 \pm 0.05 \mathrm{mg}$. All PCFC measurements are done in triplicate, and the results are averaged.

\subsubsection{Cone calorimetry}

The calorimeter cone is one of the basic test equipment in the field of fire behavior. It was developed by Babrauskas in the 1980s $[6,7]$ in order to study the heat release produced during the combustion of materials subjected to an incident radiative flux. The samples are placed in a conical shaped furnace radiating a predetermined incident flux and the amount of heat produced per time unit is measured by oxygen consumption calorimetry $[8,9]$. This experimental device meets the ISO 5660-1 [10], ISO 5660-2 [11] \& ISO 5660-3 [12] and ASTM E 1354 [13] standards. According to these standards, the characterized sample should have an area of $100 \mathrm{~mm} \times 100 \mathrm{~mm}$ and a maximum thickness of $50 \mathrm{~mm}$. Different combustion parameters can be determined using this technique such as the heat release rate (HRR) and peak of HRR (pHRR) with oxygen depletion, the effective heat of combustion (EHC), the total heat release (THR), the mass loss rate (MLR), the smoke production rate (SPR), the time to ignition and the time of flameout (TTI and TOF respectively). The evaluation of these properties was carried out using a device provided by FTT (Fire Testing Technology). Sample sheets of $100 \times 100 \times 10 \mathrm{~mm}^{3}$ and $100 \times 100 \times 6 \mathrm{~mm}^{3}$, respectively for Kyowaglas and PMMA, were exposed to the radiating cone under a range of heat fluxes $\left(25-50-75 \mathrm{~kW} / \mathrm{m}^{2}\right)$ in presence of spark igniter to force ignition. Kyowaglas sheets analyzed in this study are industrially machined so as to obtain square plates. PMMA sheets are obtained by extrusion and injection at IMT - Mines Alès. The mold of the injection molding machine has a maximum thickness of $6 \mathrm{~mm}$. This is the reason why this study involves Kyowaglas and PMMA sheets of different thicknesses. However, in order to ensure that the thickness of the PMMA samples does not affect their fire behavior, $12 \mathrm{~mm}$ thick samples, obtained by superimposing two $6 \mathrm{~mm}$ samples, are analyzed. Indeed, cone tests are performed on these PMMA samples of different thicknesses (Fig. A1 in Appendice A). The results show the same values of thermal properties (TTI, pHRR, THR, TSR, EHC, etc...) for both thicknesses. Thus, in this study, only $6 \mathrm{~mm}$ thick samples are considered. Thereby, the weight of the samples was in the range 140-150 g for Kyowaglas and $70 \mathrm{~g}$ for PMMA. Cone tests are done in duplicate for each material and each irradiance level. Good repeatability is observed between the different tests. During cone calorimeter tests at $50 \mathrm{~kW} / \mathrm{m}^{2}$, the temperature of the upper surface was measured using an infrared camera (Optris - temperature range $150-900^{\circ} \mathrm{C}$ ) that was placed above the specimen in an inclined position in order to record the temperature field of the upper surface. The distance between the specimen and the cone bottom was increased to $60 \mathrm{~mm}$ to allow a correct measurement but the heat flux was kept equal to $50 \mathrm{~kW} / \mathrm{m}^{2}$.

\subsubsection{Scanning electron microscopy (SEM)}

Scanning Electron Microscopy is an electron microscopy technique which by scanning the sample with an electron beam is able to produce images of the surface of a sample. The electron-matter interaction generates several types of emissions. The secondary electrons make it possible to image the surface of the sample, with topographic contrast. Backscattered electrons give an image with chemical contrast on a flat surface. X-ray photons make chemical analysis possible in Energy Dispersion Spectroscopy (EDS). The energy dispersive X-ray spectrometry makes it possible to obtain a quantitative or qualitative analysis of the chemical elements in a solid sample by counting the number of X-ray photons emitted by the latter during a determined time when it is bombarded by an electron beam. In this paper, micrographs were obtained under 
high vacuum using a FEI Quanta 200 environmental scanning electron microscope. Samples were cut and deposited on an adhesive silver paint. The SEM was equipped with an energy dispersive Xray spectroscopy (EDXS) using Oxford INCA Energy 300 system and a detector of $133 \mathrm{eV}$ which was used to identify lead and other elements contained in the samples.

\section{Results and discussion}

\subsection{Morphology}

Kyowaglas is a material composed of a PMMA matrix (around $70 \%_{w t}$ ) and around $30 \%$ wt of lead salts (methacrylic acid and aliphatic acid [14]). As Kyowaglas is a registered trademark, the presence of additives at low content is not excluded. Kyowaglas (Fig. 1(a)) is transparent as PMMA (Fig. 1(b)), evidencing that the $30 \%$ lead species, detected by EDXS, are not present as submicronic or micronic fillers (Fig. 2(a) and (b)).

\subsection{Thermo-physical properties of Kyowaglas and PMMA}

Thermo-physical properties are measured at room temperature and listed in Table 1. Kyowaglas and PMMA have similar thermal conductivity and diffusivity. However, a difference is noted in the specific heat and density. The fact that Kyowaglas contains lead explains the difference in density and specific heat. In general, metals have a lower $C_{p}$ value than polymers, especially since they have a higher atomic weight. Thermal effusivity is the square root of the product of $\mathrm{k}, \rho$ and $\mathrm{C}_{\mathrm{p}}$. Note that the values of PMMA thermophysical properties are consistent with the literature $[15,16]$.

\subsubsection{Decomposition at microscale}

The thermal stability of Kyowaglas and PMMA was investigated by TGA analysis. Figs. 3 and 4 show respectively the TG (Thermogravimetry) and DTG (Differential Thermogravimetry) curves of pure PMMA (red) and Kyowaglas (blue) under nitrogen flow. TGA data of Kyowaglas and PMMA are given in Table 2. The data include the temperature at which $10 \%$ weight loss occurs $\left(\mathrm{T}_{10}\right.$ : onset temperature of degradation), the temperature for $50 \%$ degradation $\left(\mathrm{T}_{50}\right)$ as the mid-point of degradation, and the amount of residue at $900^{\circ} \mathrm{C}$.

About $20 \%$ of Kyowaglas decomposed between $200^{\circ} \mathrm{C}$ and $365^{\circ} \mathrm{C}$, whereas pure PMMA decomposition started at $290^{\circ} \mathrm{C}$. On the other hand, the main decomposition of PMMA ends at $415^{\circ} \mathrm{C}$, whereas that of Kyowaglas ends at $600^{\circ} \mathrm{C}$.

Pure PMMA showed no residue (complete decomposition). When incorporating lead into PMMA, the resultant Kyowaglas composite exhibited a residual weight of about $32 \%$, which is attributed to the amount of incorporated lead. Additionally, DTG curves show one single peak for PMMA for $\mathrm{T} \approx 370^{\circ} \mathrm{C}$ (in agreement with [17]) and two different peaks for Kyowaglas $\left(\mathrm{T} \approx 340^{\circ} \mathrm{C}\right.$ and $\mathrm{T} \approx 400^{\circ} \mathrm{C}$ ) which means that the decomposition of Kyowaglas takes place in two stages. TGA analysis showed that the main decomposition phase starts at approximately the same temperature for both materials $\left(\mathrm{T}_{10}\right.$ PMMA $=330^{\circ} \mathrm{C}$ and $\left.\mathrm{T}_{10 \text { Kyowa }}=326^{\circ} \mathrm{C}\right)$.

To investigate the role of lead in the combustion of Kyowaglas, PCFC tests were also performed. The HRR PCFC $_{\text {versus tempera- }}$ ture curves (anaerobic pyrolysis) of Kyowaglas and pure PMMA are shown in Fig. 5. PMMA curve and values are in good agreement with previous results found in the literature [18]. Lead seems to alter the thermal decomposition profile of PMMA contained in Ky-
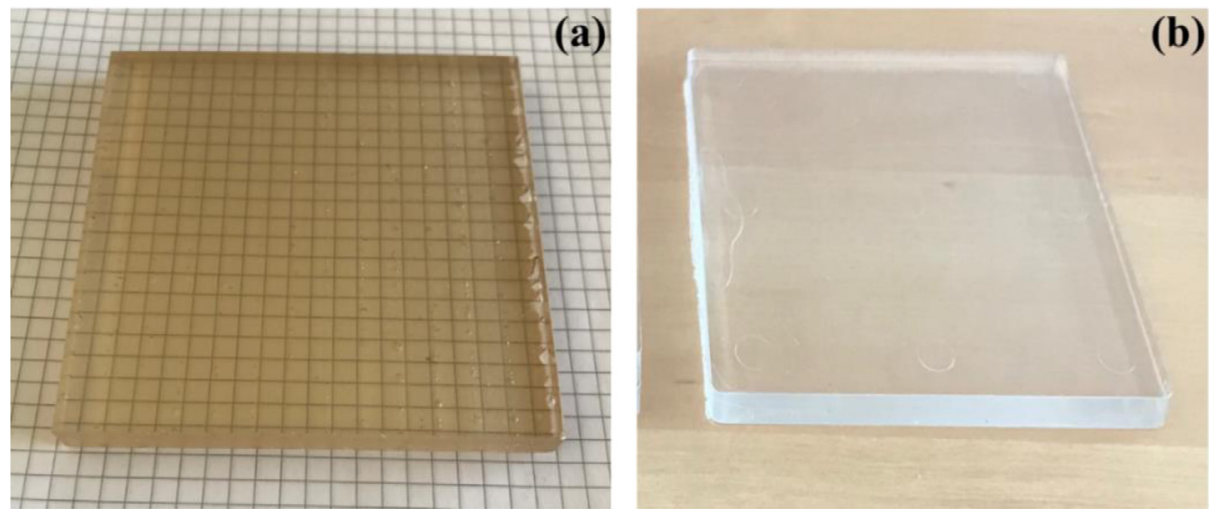

Fig. 1. (a) Kyowaglas plate $100 \times 100 \times 10 \mathrm{~mm}^{3}$ (b) PMMA plate $100 \times 100 \times 6 \mathrm{~mm}^{3}$.
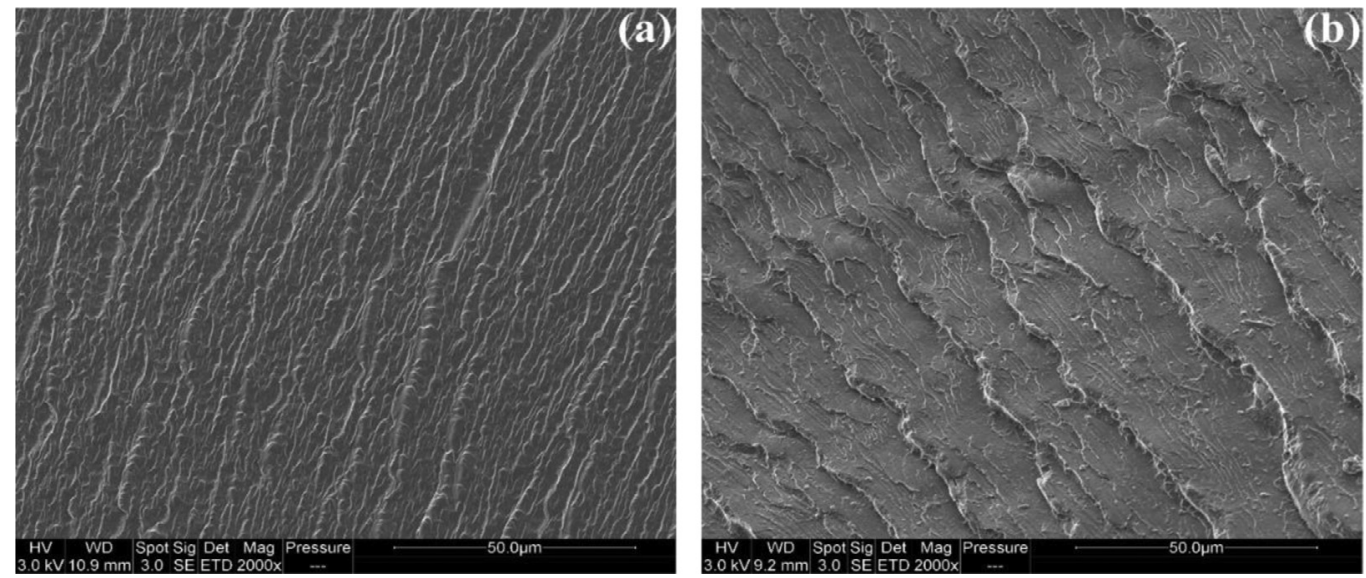

Fig. 2. SEM micrographs of (a) Kyowaglas and (b) PMMA. 
Table 1

Thermo-physical properties of Kyowaglas and PMMA at room temperature.

\begin{tabular}{llllll}
\hline & $\begin{array}{l}\text { Thermal } \\
\text { conductivity } \mathrm{k} \\
(\mathrm{W} / \mathrm{m} . \mathrm{K})\end{array}$ & $\begin{array}{l}\text { Density } \rho \\
\left(\mathrm{kg} \cdot \mathrm{m}^{-3}\right)\end{array}$ & $\begin{array}{l}\text { Specific heat Cp } \\
(\mathrm{J} \cdot \mathrm{kg} . \mathrm{K})\end{array}$ & $\begin{array}{l}\text { Thermal } \\
\text { diffusivity } \alpha \\
\left(\mathrm{m}^{2} / \mathrm{s}\right)\end{array}$ & $\begin{array}{l}\text { Thermal } \\
\text { effusivity E } \\
\left(\mathrm{W} . \mathrm{s}^{0.5} / \mathrm{m}^{2} . \mathrm{K}\right)\end{array}$ \\
\hline Kyowaglas & $0.15 \pm 1.10^{-3}$ & $1604 \pm 1.2$ & $1044 \pm 11$ & $\begin{array}{l}8.9 .10^{-8} \pm \\
6.10^{-10}\end{array}$ & $501.2 \pm 3$ \\
PMMA & $0.16 \pm 3.10^{-3}$ & $1192 \pm 1$ & $1416 \pm 8$ & $\begin{array}{l}9.2 .10^{-8} \pm \\
9.10^{-10}\end{array}$ & $520 \pm 4$ \\
\hline
\end{tabular}

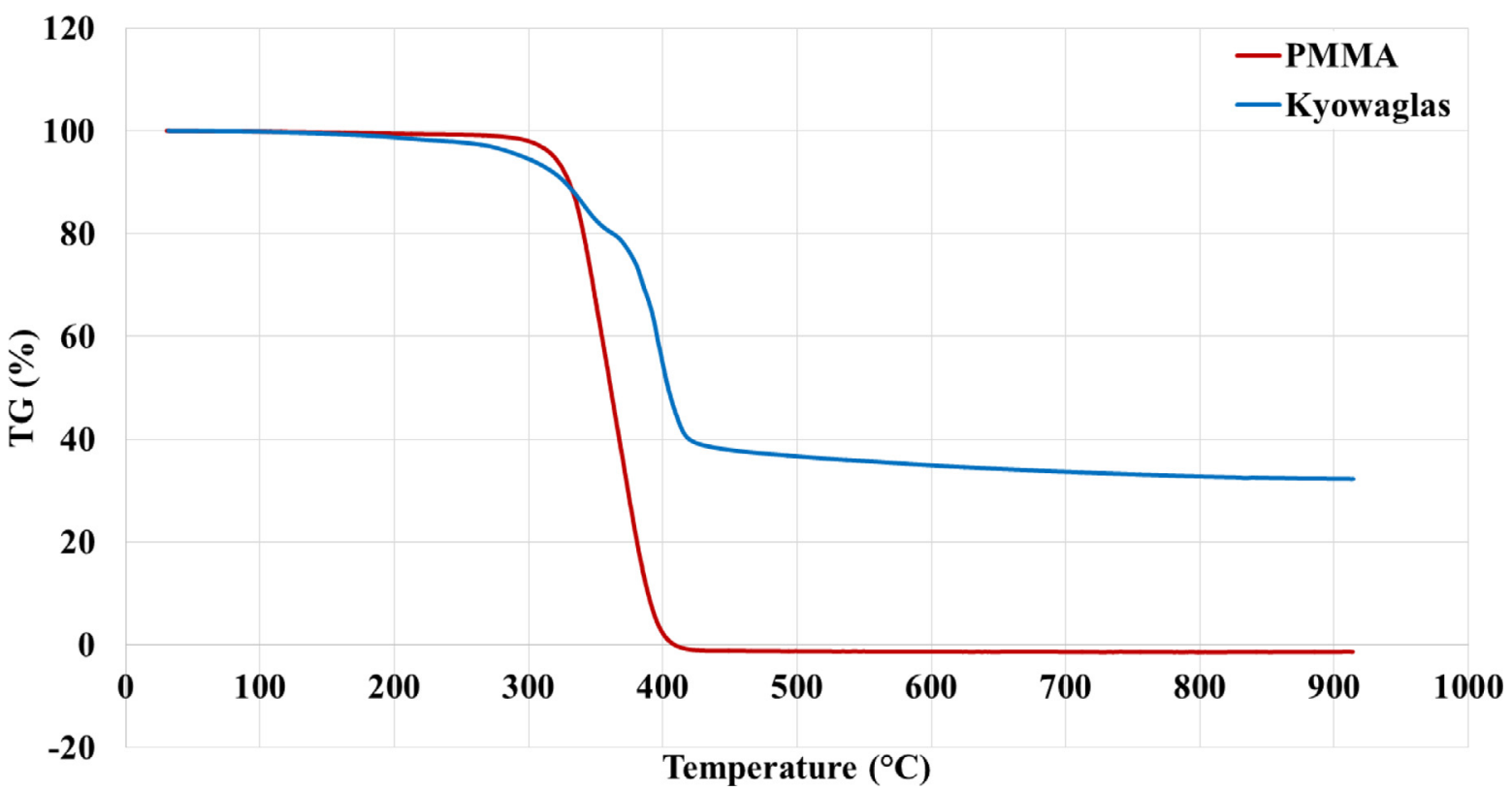

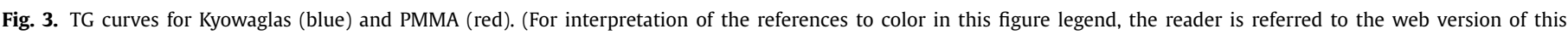
article.).

Table 2

TGA parameter of Kyowaglas and PMMA under nitrogen atmosphere.

\begin{tabular}{llll}
\hline & $\mathrm{T}_{10}\left({ }^{\circ} \mathrm{C}\right)$ & $\mathrm{T}_{50}\left({ }^{\circ} \mathrm{C}\right)$ & $\%$ Residue \\
\hline Kyowaglas & $326 \pm 1$ & $390 \pm 2$ & $32 \pm 0.2$ \\
PMMA & $330 \pm 1$ & $361 \pm 3$ & 0 \\
\hline
\end{tabular}

owaglas. Pure PMMA primarily decomposes in one-step (one peak around $385^{\circ} \mathrm{C}$ ), but Kyowaglas has a multi-step decomposition process (two peaks at $365^{\circ} \mathrm{C}$ and $400^{\circ} \mathrm{C}$ ) as seen in TGA. As seen in Figs. 4 and 5 , the incorporation of $\mathrm{Pb}$ species leads to an earlier decomposition of Kyowaglas. The first peak of Kyowaglas decomposition occurs at $365^{\circ} \mathrm{C}$ while pure PMMA decomposes around $385^{\circ} \mathrm{C}$ (Fig. 5). It was stated in a previous research work that lead and lead oxides accelerate thermal degradation of polyurethanes and isophthalate resins $[19,20]$. Thus, the early decomposition of Kyowaglas can be attributed to lead species that are contained in Kyowaglas which may accelerate its decomposition to occur at a lower temperature under an inert atmosphere.

Table 3 lists the total heat release $\left(\mathrm{THR}_{\mathrm{PCFC}}\right)$, peak of HRR $\left(\right.$ pHRR $_{\mathrm{PCFC}}$ ), residue yield (\%Residue $\mathrm{PCFC}$ ), effective heat of combustion $\left(\mathrm{EHC}_{\mathrm{PCFC}}\right)$ and $\mathrm{pHRR}$ temperature $\left(\mathrm{T}_{\mathrm{pHRR}} \mathrm{PCFC}\right)$ values for both materials obtained with PCFC measurements. According to Table 3, it is evident that the pHRR PCFC $_{\text {value of Kyowaglas is much }}$

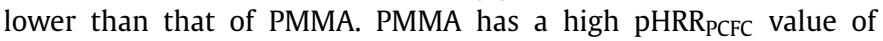
$463 \mathrm{~W} / \mathrm{g}$. As for Kyowaglas, the pHRR ${ }_{\mathrm{PCFC}}$ decreased to $158 \mathrm{~W} / \mathrm{g}$, which represents a decrease of $65.9 \%$. This decrease can be explained by a lower flammability of Kyowaglas when compared to PMMA. THR PCFC $_{\text {calculated from the total area under the HRR }}$ PCFC peaks is another important parameter for fire hazard evaluation [21]. THR $_{\text {PCFC }}$ showed the same trend as PHRR PCFC $_{\text {, with a decrease }}$ of $33.3 \%$, this value corresponds to the residue yield of Kyowaglas. Effective heat of combustion of Kyowaglas $(25 \mathrm{~kJ} / \mathrm{g}$ ) shows little change compared to that of pure PMMA $(24 \mathrm{~kJ} / \mathrm{g}$ ). Combining with the residue yields of PMMA and Kyowaglas, which are respectively 0 and 33\%, it is suggested that lead shows thermal stabilization effects that mainly occur in the condensed phase despite the slightly earlier decomposition of Kyowaglas. This thermal stability is characterized, on the one hand, by lower HRR peaks and, on the other hand, by the thermal decomposition which continues at higher temperatures. $\mathrm{T}_{\text {pHRR-PCFC }}$ values are close (around $380^{\circ} \mathrm{C}$ ) for both materials and are in good agreement with decomposition temperatures recorded with TGA. PCFC data presented here convincingly demonstrate that Kyowaglas has a lower flammability than PMMA, indicating the stabilizing role of lead in Kyowaglas.

\subsection{Fire behavior}

\subsubsection{Heat release rate (HRR)}

Charring and non-charring polymers show different temporal variations of heat release rate per unit area (Fig. 6). It should be noted that in this paper the term "char" refers to a compact residue layer rich in lead and/or lead oxide which is formed on the top of the sample as the Kyowaglas burns. In addition, the comparative study carried out between Kyowaglas and PMMA concerns samples of different thicknesses, as mentioned earlier. Indeed, Kyowaglas samples have a thickness of $10 \mathrm{~mm}$ against $6 \mathrm{~mm}$ for PMMA. However, as mentioned earlier, this difference in thickness 


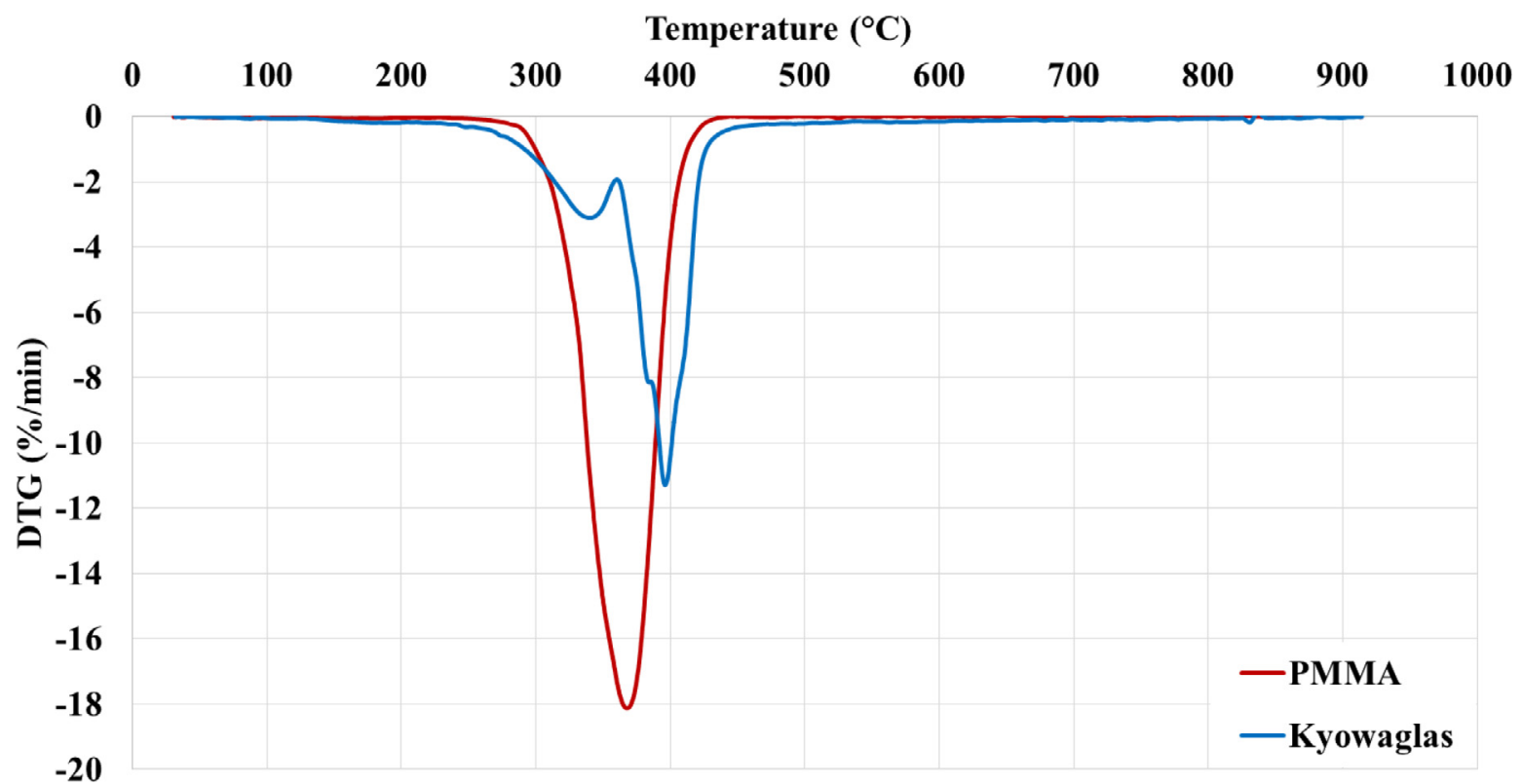

Fig. 4. DTG curves for Kyowaglas (blue) and PMMA (red). (For interpretation of the references to color in this figure legend, the reader is referred to the web version of this article.).

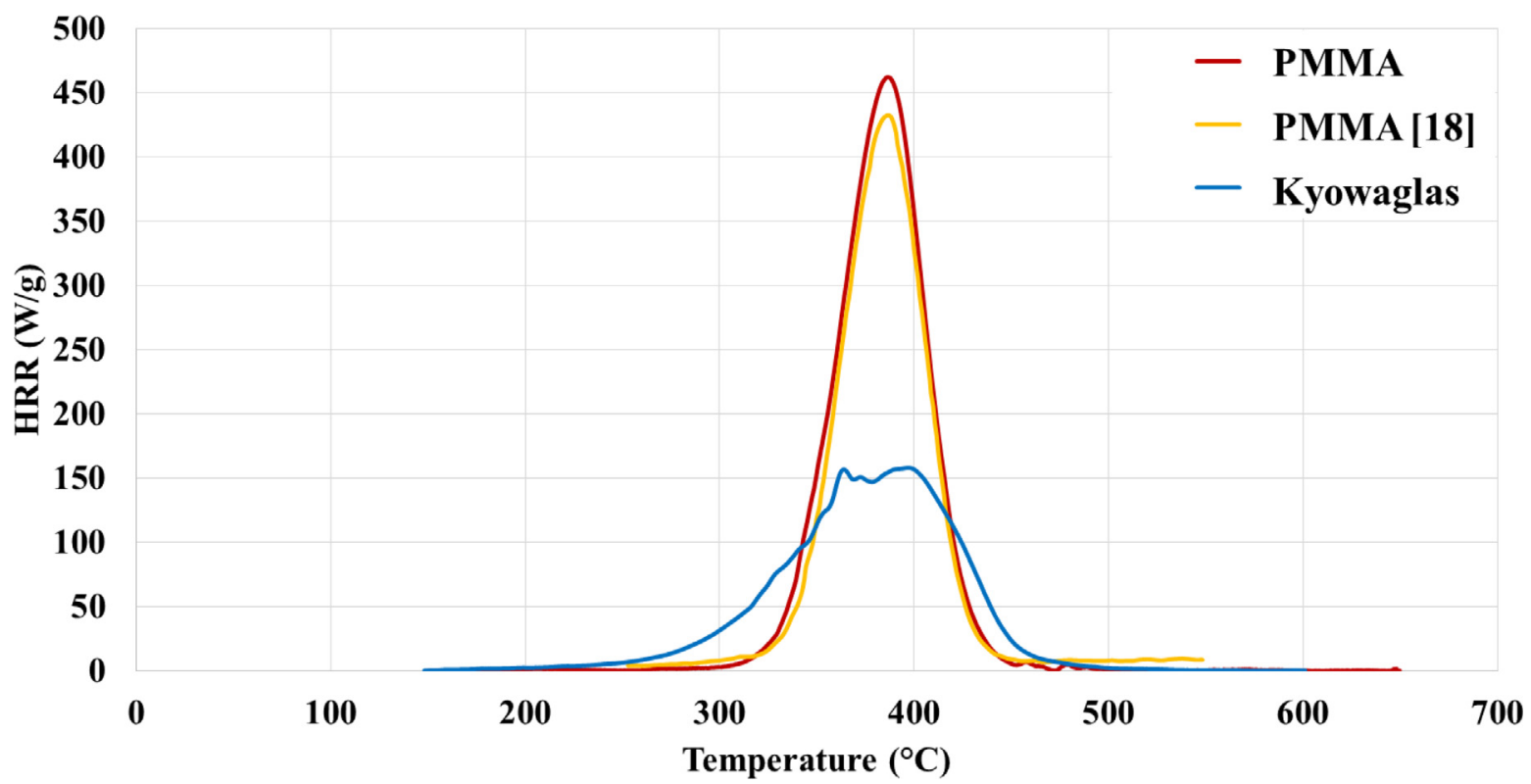

Fig. 5. Heat release rate curves for PMMA (red), PMMA data from literature [18] (yellow) and Kyowaglas (blue) in anaerobic pyrolysis conditions. (For interpretation of the references to color in this figure legend, the reader is referred to the web version of this article.).

Table 3

PCFC parameters for Kyowaglas and PMMA

\begin{tabular}{|c|c|c|c|c|c|}
\hline & $\begin{array}{l}\text { pHRR }_{\text {PCFC }} \\
\left(\mathrm{W}_{\cdot} \mathrm{g}^{-1}\right)\end{array}$ & $\operatorname{THR}_{\text {PCFC }}\left(\mathrm{kJ} \cdot \mathrm{g}^{-1}\right)$ & $\begin{array}{l}\text { \%Residue PCFC } \\
(\%)\end{array}$ & $\mathrm{EHC}_{\mathrm{PCFC}}\left(\mathrm{kJ} \cdot \mathrm{g}^{-1}\right)$ & $\begin{array}{l}\mathrm{T}_{\text {pHRR-PCFC }} \\
\left({ }^{\circ} \mathrm{C}\right)\end{array}$ \\
\hline Kyowaglas & $158 \pm 4$ & $16.6 \pm 0.2$ & $33 \pm 0.5$ & $25 \pm 0.3$ & $370-400 \pm 5$ \\
\hline PMMA & $463 \pm 8$ & $24 \pm 0.5$ & 0 & $24 \pm 0.5$ & $380 \pm 6$ \\
\hline
\end{tabular}

does not affect the values of TTI and pHRR (see Fig. A1 in Appendix A).

For non-charring polymers as PMMA (Fig. 6(a)), HRR increases continuously from ignition up to reaching a peak of heat release rate when the most important part of PMMA is decomposed [22]. This peak is followed by a sudden decrease and flame out. The thickness of the pyrolysis zone continuously increases due to the heat feedback from the flame [23]. The decomposition is very fast. Boiling of PMMA starts before piloted ignition and is observed during the whole burning phase. As already observed by different authors, the pHRR of such materials is very sensitive to heat flux [24,25]. pHRR increases strongly with heat flux.

For charring polymers, a first HRR peak shortly after pilotedignition is observed in Fig. 6(b). As the pyrolysis front progresses, 

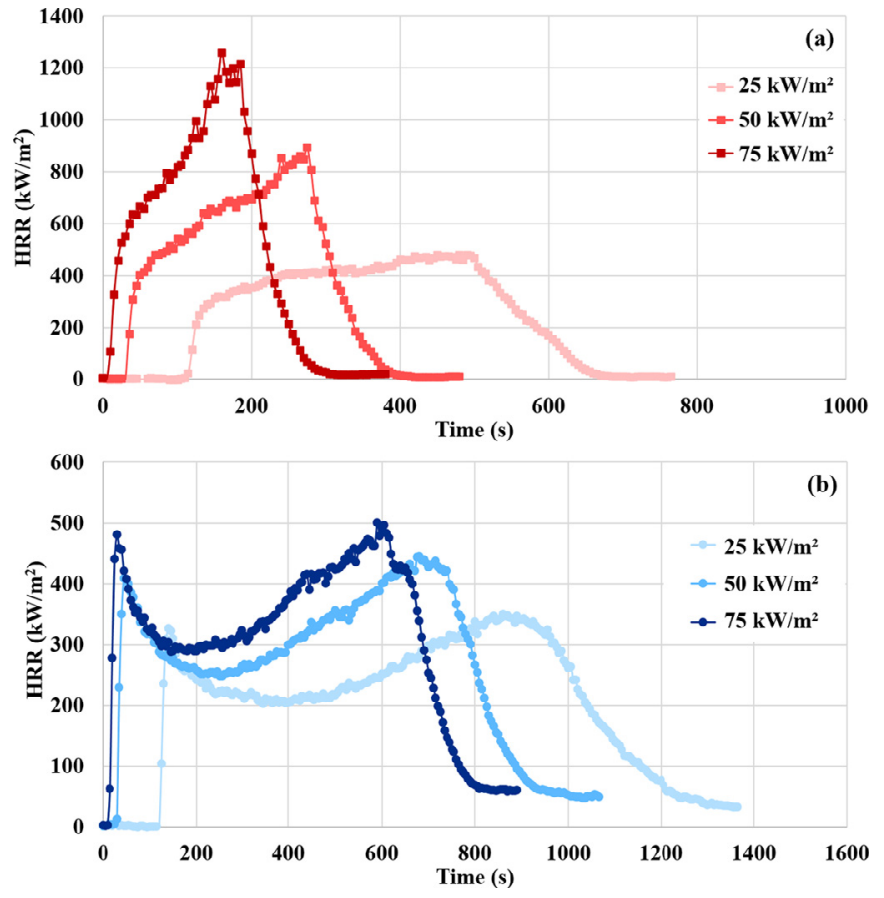

Fig. 6. HRR evolution as a function of time under different external heat fluxes for: (a) PMMA and (b) Kyowaglas. (For interpretation of the references to color in this figure legend, the reader is referred to the web version of this article.).

a heat-resistant residue layer gradually forms and accumulates between the surface of the sample and the inner virgin Kyowaglas. Consequently, the HRR decreases after the first peak. This decrease stops at a certain heat release rate depending on heat flux (from $200 \mathrm{~kW} / \mathrm{m}^{2}$ at $25 \mathrm{~kW} / \mathrm{m}^{2}$ to $300 \mathrm{~kW} / \mathrm{m}^{2}$ at $75 \mathrm{~kW} / \mathrm{m}^{2}$ ). A clear plateau is observed when the sample thickness is $23 \mathrm{~mm}$ (Appendix A - Fig. A2). This plateau proves that the burning reaches a steady state. Nevertheless, for $10 \mathrm{~mm}$-thick sample, the plateau is very short, especially at high heat flux, and a second pHRR is observed. Two explanations appear in the literature for the occurrence of this second pHRR. The first explanation concerns the continuous increase in temperature that causes cracks and evacuation paths of volatile substances in the residue layer thus formed. As the cracks go widen and deepen, the HRR reaches a maximum [26]. According to the second explanation, the second peak may be due to the insulated backside. Indeed, when the heat reaches the insulated back surface, there is an accumulation of energy due to the insulation, which results in an increase of HRR [23,26-28]. Another study also shows that increasing the thickness of the sample results in a decrease in the second maximum peak. When the sample is thick enough, its heat release rate reaches a steady state value and the second peak of HRR no longer occurs [29]. The second explanation seems more realistic since when a cone test is carried out with a thicker sample $(23 \mathrm{~mm}$ instead of $10 \mathrm{~mm}$ ), the plateau lasts for a longer time and the second peak does not appear. Therefore, this peak is considered as an artefact due to the use of rock wool to insulate the back surface and should not be taken into account. After the second peak, flaming combustion stops once the volatile pyrolysis gases are exhausted and thermooxidation takes place. The reaction then becomes oxidizer diffusion dominated [30,31].

\subsubsection{Mass loss (ML) and mass loss rate (MLR)}

Fig. 7 shows the variation of the mass loss (ML) for both studied materials as a function of time for different external heat fluxes. Regardless of the heat flux, the final mass of PMMA is zero while Kyowaglas loses almost $70 \%$ of its initial mass.

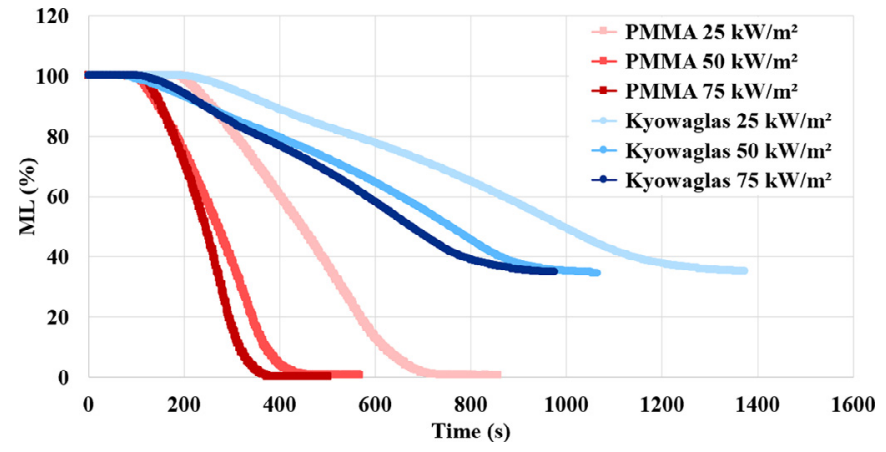

Fig. 7. Mass loss evolution as a function of time for three heat fluxes, for Kyowaglas (blue curves) and PMMA (red curves). (For interpretation of the references to color in this figure legend, the reader is referred to the web version of this article.).

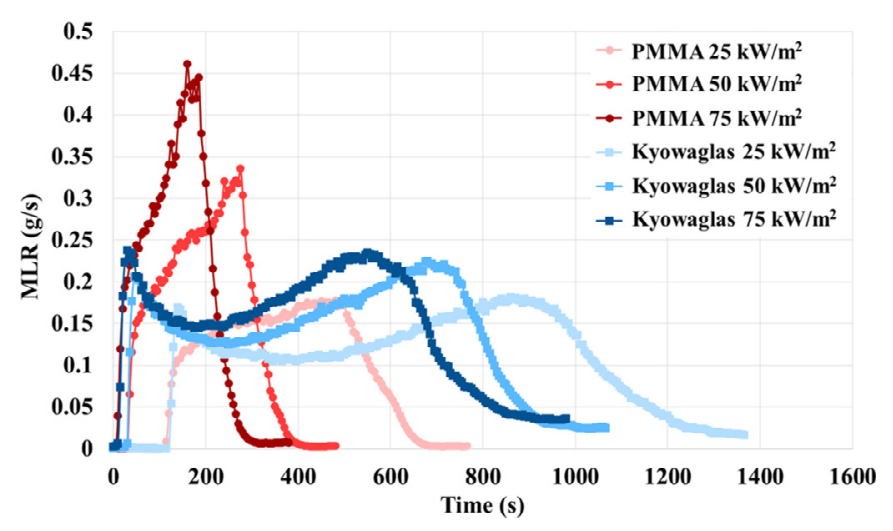

Fig. 8. Evolution of mass loss rate (MLR) as function of time for different external heat fluxes for Kyowaglas (blue curves) and PMMA (red curves). (For interpretation of the references to color in this figure legend, the reader is referred to the web version of this article.).

Table 4

Cone calorimeter tests results for Kyowaglas.

\begin{tabular}{llll}
\hline & $25 \mathrm{~kW} / \mathrm{m}^{2}$ & $50 \mathrm{~kW} / \mathrm{m}^{2}$ & $75 \mathrm{~kW} / \mathrm{m}^{2}$ \\
\hline TTI $(\mathrm{s})$ & $121 \pm 1$ & $30 \pm 2$ & $12 \pm 1$ \\
TOF $(\mathrm{s})$ & $1283 \pm 10$ & $981 \pm 50$ & $805 \pm 62$ \\
pHRR $\left(\mathrm{kW} / \mathrm{m}^{2}\right)$ & $350.7 \pm 5$ & $409 \pm 12$ & $481.1 \pm 2$ \\
$\mathrm{t} \mathrm{pHRR}(\mathrm{s})$ & $140 \pm 3$ & $45 \pm 3$ & $30 \pm 1$ \\
THR $\left(\mathrm{MJ} / \mathrm{m}^{2}\right)$ & $269.5 \pm 3$ & $279.4 \pm 1$ & $288.7 \pm 12$ \\
THR $(\mathrm{kJ} / \mathrm{g})$ & $17 \pm 0.1$ & $17.5 \pm 0.1$ & $17 \pm 0.7$ \\
Residue $(\%$ wt $)$ & $34.4 \pm 0.4$ & $33.6 \pm 0.3$ & $34.5 \pm 0.7$ \\
EHC $(\mathrm{MJ} / \mathrm{kg})$ & $26 \pm 0.1$ & $26.4 \pm 0.1$ & $25.9 \pm 0.7$ \\
TSR $\left(\mathrm{m}^{2} / \mathrm{m}^{2} . \mathrm{g}\right)$ & $24 \pm 1$ & $25 \pm 1$ & $26 \pm 2$ \\
\hline
\end{tabular}

Transient evolutions of mass loss rate (MLR) are presented in Fig. 8 for Kyowaglas and PMMA for different external heat fluxes. When the external heat flux increases from 25 to $75 \mathrm{~kW} . \mathrm{m}^{-2}$, samples' mass is lost on a shorter time. For example, in the case of Kyowaglas, mass loss takes around $16 \mathrm{~min}$ at $75 \mathrm{~kW} . \mathrm{m}^{-2}$ against $22 \mathrm{~min}$ at $25 \mathrm{~kW} \cdot \mathrm{m}^{-2}$, with a higher maximal intensity of the MLR peak around 0.24 g.s $\mathrm{s}^{-1}$ at $75 \mathrm{~kW} . \mathrm{m}^{-2}$ compared to $0.18 \mathrm{~g} . \mathrm{s}^{-1}$ at $25 \mathrm{~kW} \cdot \mathrm{m}^{-2}$. Similar phenomena are observed for PMMA. The incorporation of lead into the PMMA matrix decreases the MLR peak amplitude at a given external heat flux. For $75 \mathrm{~kW} . \mathrm{m}^{-2}$, MLR peak amplitude decreases from about 0.46 to 0.25 g.s ${ }^{-1}$ when $30 \%$ wt of $\mathrm{Pb}$-compounds are added to the PMMA matrix (Kyowaglas). The same observation can be made for other heat fluxes.

\subsubsection{Cone calorimeter parameters}

Tables 4 and 5 present the results of cone calorimeter experiments for Kyowaglas and PMMA, respectively. According to these tables, regardless of the heat flux, flammability is much lower for 
Table 5

Cone calorimeter tests results for PMMA.

\begin{tabular}{llll}
\hline & $25 \mathrm{~kW} / \mathrm{m}^{2}$ & $50 \mathrm{~kW} / \mathrm{m}^{2}$ & $75 \mathrm{~kW} / \mathrm{m}^{2}$ \\
\hline TTI $(\mathrm{s})$ & $114 \pm 4$ & $31 \pm 1$ & $8 \pm 1$ \\
TOF $(\mathrm{s})$ & $662 \pm 32$ & $397 \pm 7$ & $296 \pm 16$ \\
$\mathrm{pHRR}\left(\mathrm{kW} / \mathrm{m}^{2}\right)$ & $479 \pm 29$ & $894 \pm 31$ & $1257 \pm 13$ \\
$\mathrm{t}$ pHRR $(\mathrm{s})$ & $490 \pm 2$ & $275 \pm 3$ & $160 \pm 3$ \\
THR $\left(\mathrm{MJ} / \mathrm{m}^{2}\right)$ & $190 \pm 3$ & $188 \pm 6$ & $192 \pm 0.7$ \\
THR $(\mathrm{kJ} / \mathrm{g})$ & $23.9 \pm 0.6$ & $23.5 \pm 0.1$ & $24.1 \pm 0.1$ \\
Residue $(\% \mathrm{wt})$ & 0 & 0 & 0 \\
EHC $(\mathrm{MJ} / \mathrm{kg})$ & $23.9 \pm 0.6$ & $23.5 \pm 0.1$ & $24.1 \pm 0.1$ \\
TSR $\left(\mathrm{m}^{2} / \mathrm{m}^{2} . \mathrm{g}\right)$ & $12 \pm 2$ & $14 \pm 1$ & $13 \pm 1$ \\
\hline
\end{tabular}

Kyowaglas than for PMMA. For example, pHRR and THR of Kyowaglas at $25 \mathrm{~kW} / \mathrm{m}^{2}$ are $350 \mathrm{~kW} / \mathrm{m}^{2}$ and $17 \mathrm{~kJ} / \mathrm{g}$, versus $480 \mathrm{~kW} / \mathrm{m}^{2}$ and $24 \mathrm{~kJ} / \mathrm{g}$ for PMMA, corresponding to reductions of $27 \%$ and $29 \%$ respectively. Higher is the heat flux, higher is the reduction in pHRR recorded for Kyowaglas. Regarding EHC values, PMMA shows similar values of EHC in the cone tests and PCFC under anaerobic conditions (Table 3). However, the EHC values obtained for Kyowaglas in the cone tests are slightly higher than those obtained with PCFC. This is probably due to lead oxidation during cone calorimeter testing due to the presence of oxygen especially towards the end of the tests.

Compared with PMMA, Kyowaglas has a very dense and strong self-formed residue layer which reduces the heat transfer and the flow rate of volatiles, maintaining a HRR at a lower value (plateau in Fig. 6). According to Schartel and Hull [26], PMMA exhibits thermally thick non-charring behavior, unlike Kyowaglas, which exhibits thermally thick charring behavior.

\subsubsection{Thermal behavior}

Homogeneous materials can be classified mainly into two categories: thermally "thick" and thermally "thin" materials. A material can be considered thermally "thin" when the temperature variation across its thickness is negligible for a given period of time [32]. Otherwise, it is considered thermally "thick". For thermally thick materials, the depth of thermal penetration $\delta$, which characterizes the speed of penetration and the attenuation of a thermal wave in a medium, is less than its physical thickness (10 and $6 \mathrm{~mm}$ for Kyowaglas and PMMA, respectively) [33-35]. In this case, a temperature gradient is created between the two opposite sides [36,37]. $\delta$ is calculated as follows:

$\delta \approx \sqrt{\alpha \cdot T T I}$

where TTI is the time to ignition (s) and $\alpha$ is the thermal diffusivity $\left(\mathrm{m}^{2} / \mathrm{s}\right)$.

Table 6 indicates that Kyowaglas and PMMA are considered thermally "thick", for the three irradiances studied, as long as their thickness is much higher than $3.3 \mathrm{~mm}$ and $3.2 \mathrm{~mm}$, respectively. This is in good agreement with the findings drawn from the HRR curve shape discussed above. As a matter of fact, it was stated that thermally thick non-residue forming samples, like PMMA, show a strong initial increase after ignition up to a quasi-static HRR value. The latter is marked by a plateau for low irradiance levels and by a shoulder for high irradiance levels as shown in Fig. 6(a). The quasi-steady HRR remains until the pHRR occurs towards the end of the test [26]. Concerning thermally thick residue forming samples, an initial increase in HRR is observed until the formation of a residue layer that thickens with time. This results in a decrease in HRR [26]. Kyowaglas shows a similar behavior as can be seen in Fig. 6(b).

\subsubsection{Ignition temperature $\left(T_{i g}\right)$ and critical heat flux (CHF)}

Among the parameters that allow the characterization of the fire risk and the decomposition of materials, time to ignition (TTI) is considered as a critical parameter [24,38,39]. A sample with a low TTI exhibits a high fire risk and reduced thermal resistance. The relation between TTI and heat flux makes it possible to evaluate the flammability properties of the material such as ignition temperature $\left(\mathrm{T}_{\mathrm{ig}}\right)$ and critical heat flux $(\mathrm{CHF})$. The latter corresponds to the minimum heat flux for which the surface of the sample reaches ignition temperature marking the start of ignition [35]. Time to ignition data, for Kyowaglas and PMMA, under different heat fluxes are listed in Tables 4 and 5, respectively. Both materials exhibit similar TTI at fixed heat flux, meaning that the presence of lead compounds have no significant effect on ignition.

In the literature, various authors have proposed models and theories relating TTI, incident radiant heat flux and thermophysical properties of materials in order to better understand their thermal decomposition. Some of these theories were developed under the assumption that radiation does not penetrate into the solid phase. However, it must be borne in mind that clear PMMA behaves as a semi-transparent material when subjected to thermal radiation [40]. Unlike perfectly transparent materials, semitransparent materials absorb radiation. This absorption takes place in depth not just at the surface, in contrast with opaque bodies, and plays a major role in the heating and the ignition of the material [41]. Hence, predictions and models that assume that there's no in-depth absorption of radiation, do not apply to clear PMMA. In this paper, reference is made to Jiang's model [42] for the description of the temperature field in the material when subjected to a constant heat flux, which is the case of cone calorimeter tests. This model considers a semi-infinite medium which absorbs radiation according to Beer's law with an absorption coefficient $\kappa$. Under these conditions, the heat equation in the sample is given by Eq. (3):

$\frac{\partial^{2} \theta}{\partial x^{2}}-\frac{\rho C_{P}}{k} \frac{\partial \theta}{\partial t}=-\frac{(1-r) \dot{q}_{e}^{\prime \prime} \kappa}{k} e^{-\kappa x}$

where $\theta=\mathrm{T}-\mathrm{T}_{0}$ is the temperature rise, $\mathrm{x}$ is the in-depth distance and $r$ is the surface reflectivity.

The initial and boundary conditions are as follows:

$\theta(x, 0)=0$
$\left\{-\left.k \frac{\partial \theta}{\partial x}\right|_{x=0}=-h_{C}\left(T_{S}-T_{0}\right)-\varepsilon \sigma\left(T_{S}^{4}-T_{0}^{4}\right)\right.$
$\theta(\infty, t)=0$

where $T_{S}$ is the surface temperature.

Moreover, for the radiated flux the following approximation is introduced:

$\sigma\left(T_{S}^{4}-T_{0}^{4}\right) \approx h_{R}\left(T_{S}-T_{0}\right)$

where $h_{R}$ is the radiation approximation coefficient.

Using Laplace transform, the analytical solution of Eqs. (3) and (4) is as follows:

$$
\begin{aligned}
\theta(x, t)= & T(x, t)-T_{0}=-\beta_{a} T_{0} e^{-\kappa x} \\
& +\frac{\beta_{a} T_{0}}{2} e^{\kappa^{2} \alpha t-\kappa x} \operatorname{erfc}\left(\kappa \sqrt{\alpha t}-\frac{x}{2 \sqrt{\alpha t}}\right) \\
& +\frac{\beta_{a} T_{0}\left(1+\beta_{L}\right)}{2\left(1-\beta_{L}\right)} e^{\kappa^{2} \alpha t+\kappa x} \operatorname{erfc}\left(\kappa \sqrt{\alpha t}+\frac{x}{2 \sqrt{\alpha t}}\right) \\
& -\frac{\beta_{a} T_{0}}{\beta_{L}\left(1-\beta_{L}\right)} e^{\beta_{L}^{2} \kappa^{2} \alpha t+\beta_{L} \kappa x} \operatorname{erfc}\left(\beta_{L} \kappa \sqrt{\alpha t}+\frac{x}{2 \sqrt{\alpha t}}\right) \\
& +\frac{\beta_{a} T_{0}\left(1+\beta_{L}\right)}{\beta_{L}} \operatorname{erfc}\left(\frac{x}{2 \sqrt{\alpha t}}\right)
\end{aligned}
$$

where $\beta_{a}=\frac{(1-r) \dot{q}_{e}^{\prime \prime}}{\kappa k T_{0}}$ and $\beta_{L}=\frac{\left(h_{c}+\varepsilon h_{R}\right)}{\kappa k}$ are ratios of heat transfer coefficients. $\beta_{a}$ is the ratio of the non-reflected incident heat flux to the in-depth heat transfer, and $\beta_{L}$ is the ratio of the convective 
Table 6

Thermal penetration depth calculation for Kyowaglas and PMMA.

\begin{tabular}{lll}
\hline & External Heat flux $\dot{q}_{e}^{\prime \prime}\left(\mathrm{kW} / \mathrm{m}^{2}\right)$ & Thermal penetration depth $\delta(\mathrm{mm})$ \\
\hline Kyowaglas & 25 & $3.3 \pm 0.01$ \\
& 50 & $1.6 \pm 0.02$ \\
PMMA & 75 & $1 \pm 0.02$ \\
& 25 & $3.2 \pm 0.03$ \\
& 50 & $1.7 \pm 0.02$ \\
& 75 & $0.9 \pm 0.03$ \\
\hline
\end{tabular}

Table 7

Kyowaglas and PMMA properties and constants used in the analysis.

\begin{tabular}{lll}
\hline & Kyowaglas & PMMA \\
\hline $\mathrm{k}(\mathrm{W} / \mathrm{m} . \mathrm{K})$ & $0.15 \pm 0.01$ & $0.16 \pm 3.10^{-3}$ \\
$\rho\left(\mathrm{kg} / \mathrm{m}^{3}\right)$ & $1604 \pm 1.2$ & $1192 \pm 1$ \\
$\mathrm{Cp}(\mathrm{J} / \mathrm{kg} \cdot \mathrm{K})$ & $1044 \pm 11$ & $1416 \pm 8$ \\
$\alpha\left(\mathrm{m}^{2} / \mathrm{s}\right)$ & $8.9 .10^{-8} \pm 6.10^{-10}$ & $9.2 .10^{-8} \pm 9.10^{-10}$ \\
$\mathrm{~h}_{\mathrm{C}}\left(\mathrm{W} / \mathrm{m}^{2} . \mathrm{K}\right)[44,45]$ & 10 & 10 \\
$\kappa\left(\mathrm{m}^{-1}\right)[42,43]$ & 960 & 960 \\
$\varepsilon[43]$ & 0.86 & 0.86 \\
$\mathrm{r}[43]$ & 0.04 & 0.04 \\
$\mathrm{~h}_{\mathrm{R}}\left(\mathrm{W} / \mathrm{m}^{2} . \mathrm{K}\right)[42]$ & 21.5 & 21.5 \\
$\dot{\boldsymbol{q}}_{e}^{\prime \prime}\left(\mathrm{W} / \mathrm{m}^{2}\right)$ & $50000 \pm 5 \%$ & $50000 \pm 5 \%$ \\
\hline
\end{tabular}

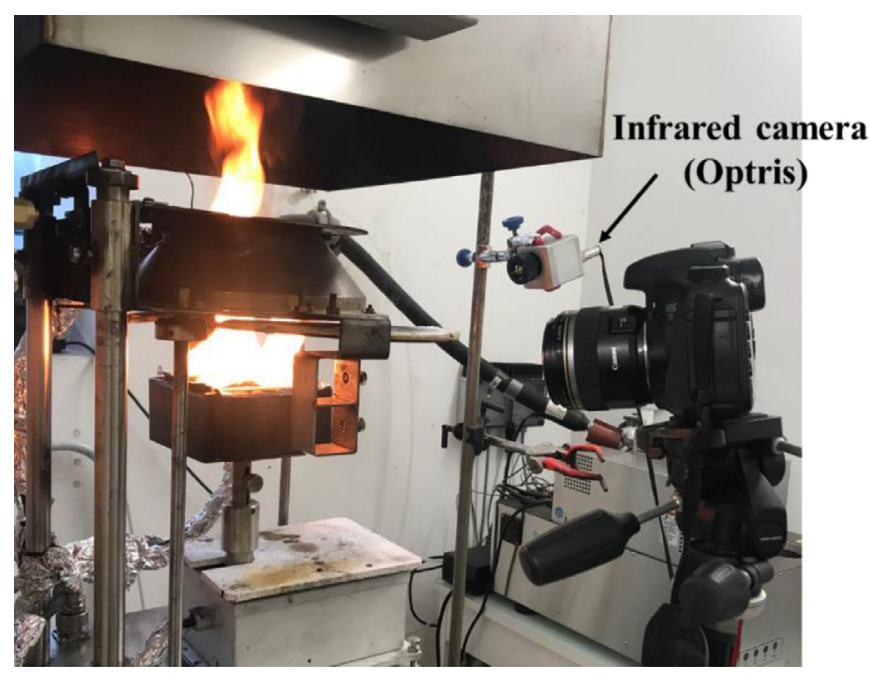

Fig. 9. Cone calorimeter test during which surface temperature is measured using an infrared camera.

and radiative heat losses from the surface to the environment. $\varepsilon$ is the emissivity $(\varepsilon=1-\mathrm{r})$.

Table 7 gathers the values of the various parameters mentioned in Eq. (6) for clear PMMA and Kyowaglas that are studied in this paper. The value of the absorption coefficient $\kappa$ is that given by Jiang, which is similar to that given by Linteris [43]. The values of $\varepsilon$ and $\mathrm{r}$ are correlated and given by manufacturer and are in good agreement with those given by Linteris as well [43]. The value of $\mathrm{h}_{\mathrm{R}}$, that reflects a linear approximation of radiation losses, was determined by the least squares method by minimizing the difference between the linear curve and the $\mathrm{T}^{4}$ curve within the interval $\left[\mathrm{T}_{0^{-}}\right.$ $\mathrm{T}_{\mathrm{ig}}$ ]. According to Jiang [42], $\mathrm{h}_{\mathrm{R}}$ value slightly varies between 20 and $24 \mathrm{~W} / \mathrm{m}^{2} . \mathrm{K}$ which is in good agreement with the calculated value in Table 7. Since $\kappa$ and $\varepsilon$ values of Kyowaglas are not known they are assumed to be identical to that of PMMA.

In this study, surface temperature is measured using infrared camera for PMMA and Kyowaglas at $50 \mathrm{~kW} / \mathrm{m}^{2}$ as shown in Fig. 9. One should note that during cone calorimeter tests equipped with infrared camera, the distance between the specimen and the cone bottom is $60 \mathrm{~mm}$ instead of $25 \mathrm{~mm}$ for tests without a camera.
In these conditions, TTI for Kyowaglas and PMMA are 65 and 38 seconds, respectively.

Fig. 10 represents experimental curves of the variation of the surface temperature for Kyowaglas and PMMA as a function of time under an irradiance level of $50 \mathrm{~kW} / \mathrm{m}^{2}$. It also shows the curve obtained with Jiang's model. On this figure, infrared camera allows measuring the ignition temperature $\left(T_{i g}\right)$ that is defined as the onset of the sudden rise in temperature [45]. The time corresponding to the onset of the sudden rise in temperature occurs at the ignition times of Kyowaglas and PMMA. Experimental $\mathrm{T}_{\mathrm{ig}}$ for Kyowaglas and PMMA are $372^{\circ} \mathrm{C}$ and $382^{\circ} \mathrm{C}$, respectively. Both materials exhibit similar $\mathrm{T}_{\mathrm{ig}}$ which are in good agreement with values obtained with PCFC. Additionally, Fig. 10 shows that the agreement between experimental data and Jiang's prediction model is satisfactory, especially during the initial rise in temperature (for $\mathrm{T} \leq$ $350^{\circ} \mathrm{C}$ ). For temperatures above $350^{\circ} \mathrm{C}$, the model no longer fit with the experimental data, this is probably due to differentiated thermal phenomena observed for the two materials. Indeed, PMMA exhibits a bubbling phenomenon while a residue layer starts to form for Kyowaglas.

Correlations between TTI and incident heat flux $\dot{\mathrm{q}}_{\mathrm{e}}^{\prime \prime}$ can be obtained from approximate solutions. For thermally thin materials, correlation shows that $\frac{1}{T T 1} \propto \dot{\mathrm{q}}_{\mathrm{e}}^{\prime \prime}$ while for thermally thick materials $\frac{1}{\sqrt{T T I}} \propto \dot{\mathrm{q}}_{\mathrm{e}}^{\prime \prime}[46,47]$. As mentioned earlier in \$3.3.4, PMMA and Kyowaglas are considered as thermally thick materials. Fig. 11 shows the variation of experimental values of $\mathrm{TTI}^{-1 / 2}$ as a function of the incident heat flux as well as the TTI values obtained from Jiang's model for PMMA and Kyowaglas. Jiang considers TTI as the time required for the surface $(\mathrm{x}=0)$ to reach the ignition temperature $\left(\mathrm{T}_{\text {ig }}\right.$ ), namely $372^{\circ} \mathrm{C}$ and $382^{\circ} \mathrm{C}$ for Kyowaglas and PMMA, respectively. This figure shows that Jiang's model describes TTI values quite well for low external heat fluxes. However, the model deviates from experimental data for high irradiance levels.

Jiang's model, as represented in Fig. 11, can be described by a parabolic law whose equation is given on the graph for each material. As it is typically observed in piloted ignition tests, (TTI) ${ }^{-1 / 2}$ decreases with a decrease in the incident heat flux, approaching a limit value that is identified as the critical heat flux (CHF) $[24,48]$. Hence, the extrapolation of Jiang's curves gives an intersection with the abscissa axis that corresponds to CHF. Kyowaglas and PMMA show close values of CHF, namely 5.4 and $5.6 \mathrm{~kW} / \mathrm{m}^{2}$, respectively. CHF value for PMMA is in good agreement with the literature $[44,48]$.

\subsubsection{Specific mass loss rate (SMLR)}

The specific mass loss rate is determined as the ratio between MLR and the sample area [24] $\left(A=88.4 \mathrm{~cm}^{2}\right)$ that is specified according to the ISO 5660 standard [49]. Experimental average SMLR (SMLR) for Kyowaglas and PMMA are plotted in Fig. 12 as function of external heat flux. $\overline{\text { SMLR }}$ increases as the external heat flux increases. For example, it goes from 14 up to $32 \mathrm{~g} / \mathrm{m}^{2} . s$ and from 8 up to $21 \mathrm{~g} / \mathrm{m}^{2}$.s, for PMMA and Kyowaglas respectively, when external heat flux increases from 25 to $75 \mathrm{~kW} / \mathrm{m}^{2}$. However, the dependence of SMLR on external heat flux is more remarkable for PMMA than for Kyowaglas. 


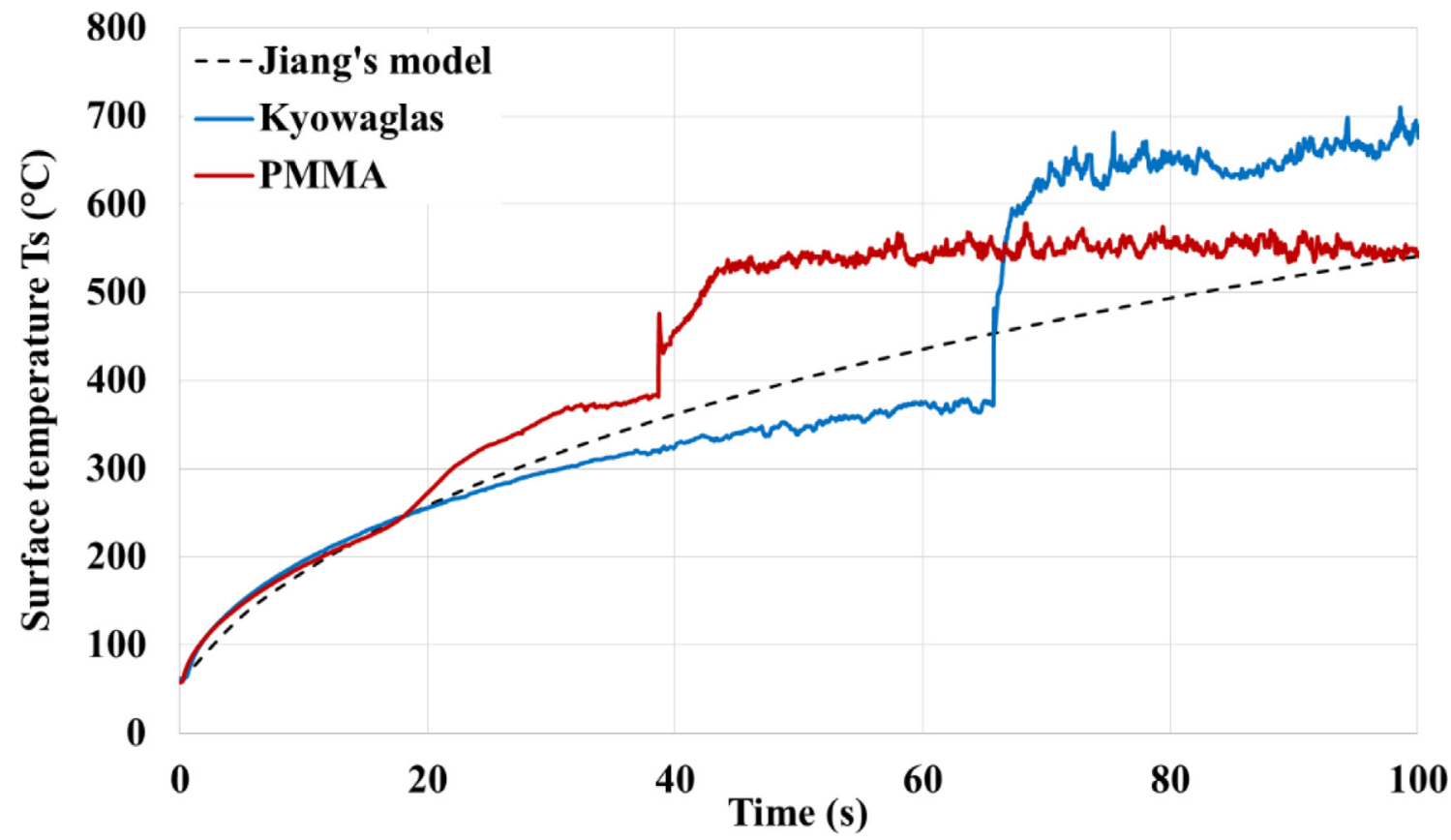

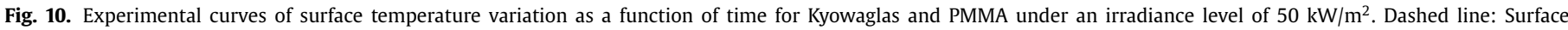

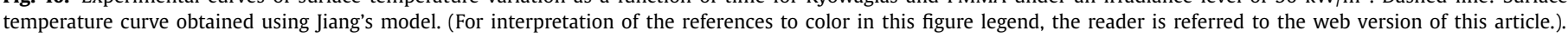

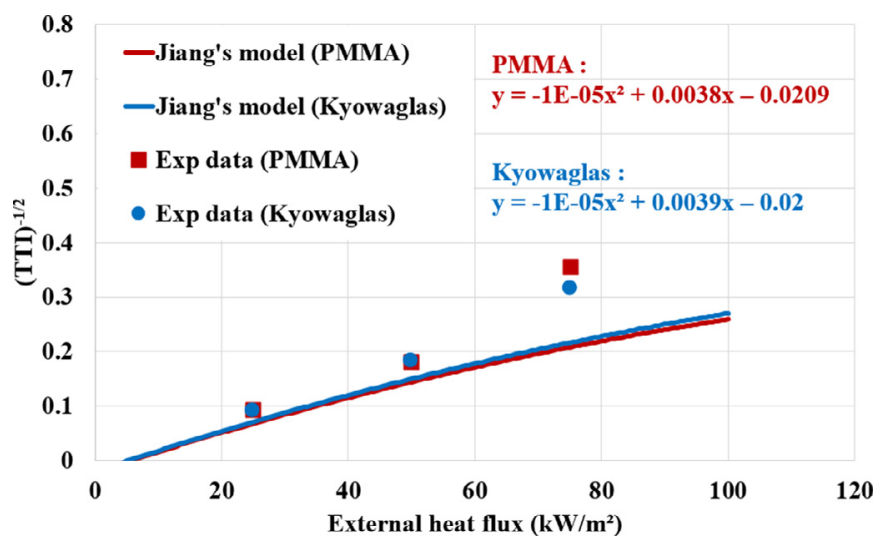

Fig. 11. $(\mathrm{TTI})^{-1 / 2}$ variation as a function of external heat flux for PMMA and Kyowaglas compared to Jiang's model that is applied for each material.

\subsubsection{Heat of gasification $\left(\Delta H_{g}\right)$}

SMLR is defined by Eq. (7) as the sum of the external heat flux $\left(\dot{q}_{e}^{\prime \prime}\right)$ and the heat flux from the flame $\left(\dot{q}_{f l}^{\prime \prime}\right)$, less the radiative heat flux loss $\left(\varepsilon \sigma T_{i g}^{4}\right)$, divided by the latent heat of gasification $\left(\Delta \mathrm{H}_{\mathrm{g}}\right)$ $[24,45]$.

$S M L R=\left(\frac{1}{\Delta H_{g}}\right) \dot{q}_{e}^{\prime \prime}+\left(\frac{\dot{q}_{f l}^{\prime \prime}-\varepsilon \sigma T_{i g}^{4}}{\Delta H_{g}}\right)$

The heat of gasification $\Delta \mathrm{H}_{\mathrm{g}}$ of a solid is defined as the heat required/absorbed to change one unit mass of solid at its boiling point into volatile products under standard atmospheric pressure. The slopes (0.267 and 0.3581) of Kyowaglas and PMMA data, respectively, obtained from Fig. 12 allow the computation of $\Delta \mathrm{H}_{\mathrm{g}}$ by using the inverse of the slope of Eq. (7). Thus, the values of $\Delta \mathrm{H}_{\mathrm{g}}$

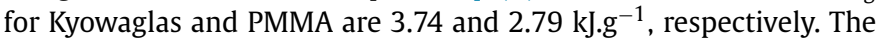
results show that the incorporation of leaded compounds generates an increase in the latent heat of gasification. This means that lead species might act as heat sinks by absorbing the heat from the polymer. As a result, the energy required for gasification be-

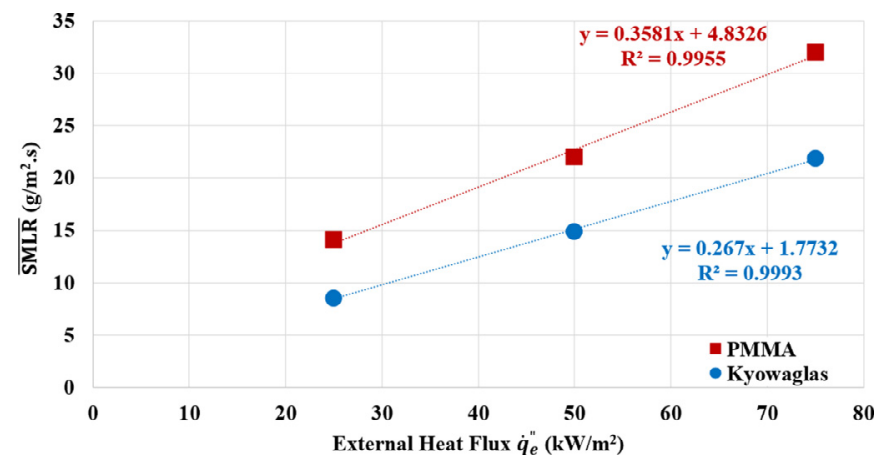

Fig. 12. Averaged Specific Mass Loss Rate as a function of external heat flux for PMMA (red) and Kyowaglas (blue). (For interpretation of the references to color in this figure legend, the reader is referred to the web version of this article.).

comes greater and the resistance of the Kyowaglas to produce a mixture of combustible gases increases which can result in a better thermal resistance. The flame heat flux $\dot{q}_{f l}^{\prime \prime}$ can also be calculated using Eq. (7). For Kyowaglas and PMMA, $\dot{q}_{f l}^{\prime \prime}$ is approximately 8.7 and $17.8 \mathrm{~kW} . \mathrm{m}^{-2}$, respectively. $\Delta \mathrm{H}_{\mathrm{g}}$ and $\dot{q}_{f l}^{\prime \prime}$ values for PMMA are in good agreement with previous results from the literature $[24,32,44,45,50,51]$.

\subsubsection{Smoke production}

Smoke Production Rate (SPR) was also recorded for both materials at three irradiances 25, 50 and $75 \mathrm{~kW} / \mathrm{m}^{2}$. Fig. 13(a) and (b) show the SPR as function of time for PMMA and Kyowaglas, respectively. In this figure, for an irradiance level of $25 \mathrm{~kW} / \mathrm{m}^{2}$, PMMA begins to emit smoke around $t=115 \mathrm{~s}$ which corresponds to its time to ignition, thereafter this smoke rate remains constant around $0.015 \mathrm{~m}^{2} / \mathrm{s}$. Kyowaglas emits smoke slightly later than PMMA from $\mathrm{t}=125 \mathrm{~s}$ which also corresponds to its time to ignition. When compared to Fig. 6, smoke production is triggered during the initial sudden increase of HRR for both materials. The amount of smoke produced during the combustion of Kyowaglas 

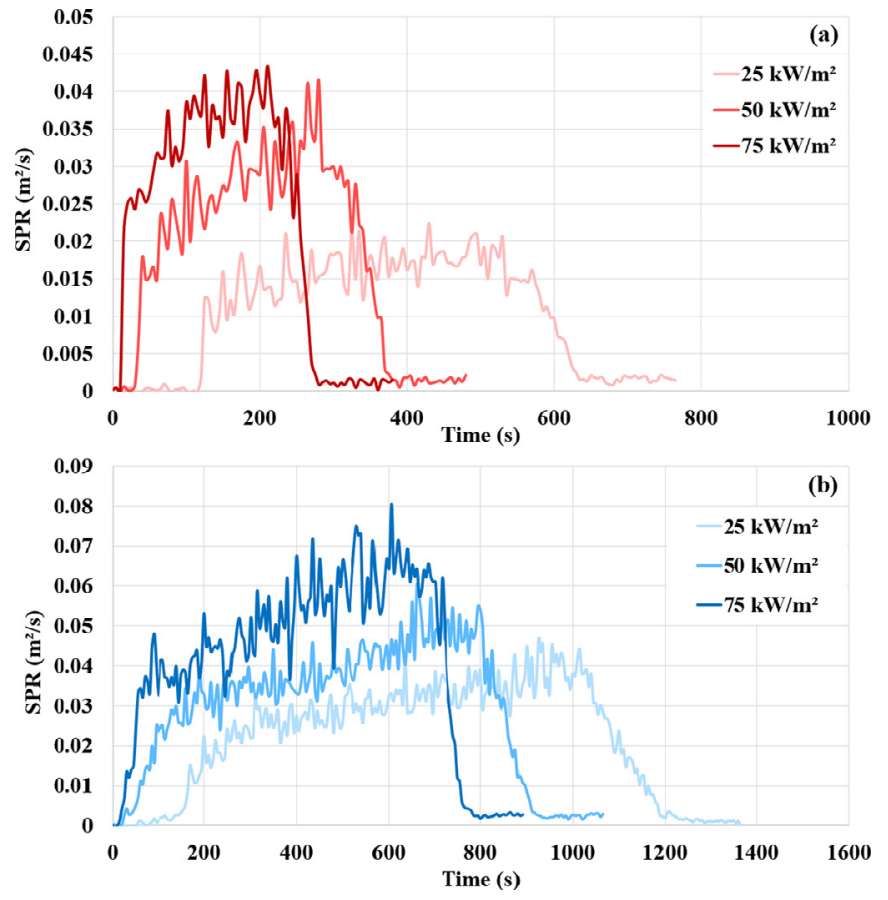

Fig. 13. SPR as function of time for (a) PMMA and (b) Kyowaglas at different irradiance levels. (For interpretation of the references to color in this figure legend, the reader is referred to the web version of this article.).

Table 8

TSR values for PMMA and Kyowaglas at 25, 50 and 75 $\mathrm{kW} / \mathrm{m}^{2}$.

\begin{tabular}{lll}
\hline & \multicolumn{2}{l}{ Total Smoke } \\
& PMMA & Kyowase TSR $\left(\mathrm{m}^{2} / \mathrm{m}^{2} . \mathrm{g}\right)$ \\
\hline $25 \mathrm{~kW} / \mathrm{m}^{2}$ & $12.7 \pm 0.2$ & $24.1 \pm 0.1$ \\
$50 \mathrm{~kW} / \mathrm{m}^{2}$ & $14.1 \pm 0.1$ & $25 \pm 0.1$ \\
$75 \mathrm{~kW} / \mathrm{m}^{2}$ & $13.8 \pm 0.2$ & $26.7 \pm 0.2$ \\
\hline
\end{tabular}

increases continuously over time until reaching a peak which appears towards the end of the test with a maximum of about 0.04 and $0.07 \mathrm{~m}^{2} / \mathrm{s}$ for irradiance levels of 25 and $75 \mathrm{~kW} / \mathrm{m}^{2}$, respectively. This maximum corresponds to the second pHRR and is followed by a fast decrease up to flame out.

Table 8 shows total smoke release (TSR) values for both studied materials at different irradiance levels. Results show that PMMA and Kyowaglas both exhibit an almost constant amount of smoke for the different irradiance levels. The latter is approximately 13 and $25 \mathrm{~m}^{2} / \mathrm{m}^{2}$.g for PMMA and Kyowaglas, respectively. Furthermore, Table 8 shows that the Kyowaglas produces twice as much smoke as PMMA despite a lower amount of gas release.

Smoke production depends on the nature and the amount of materials but also on the decomposition rate. In order to get new insights on smoke production, Fig. 14(a) and (b) plot Smoke Release Rate (RSR) versus HRR as proposed in a previous paper [52] for PMMA and Kyowaglas, respectively. RSR, like TSR, is one of the different smoke parameters that are provided by standard cone calorimeter tests. It is given by the extinction coefficient multiplied by the flow rate through the duct divided by the exposed surface area of sample $\left(88.4 \mathrm{~cm}^{2}\right)$. Even if the curves of Fig. 14 are noisy, clear differences appear between PMMA and Kyowaglas irrespective of the decomposition rate. For PMMA, RSR increases slowly with HRR. Indeed, RSR values are around $2\left(\mathrm{~m}^{2} / \mathrm{s}\right) / \mathrm{m}^{2}$ and $4\left(\mathrm{~m}^{2} / \mathrm{s}\right) / \mathrm{m}^{2}$ for HRR equal to 400 and $800 \mathrm{~kW} / \mathrm{m}^{2}$, respectively. The ratio $R S R / H R R$ (called $A$ in [52]) is close to $0.005 \mathrm{~m}^{2} / \mathrm{kJ}$ in good agreement with our previous findings. For Kyowaglas, after the first
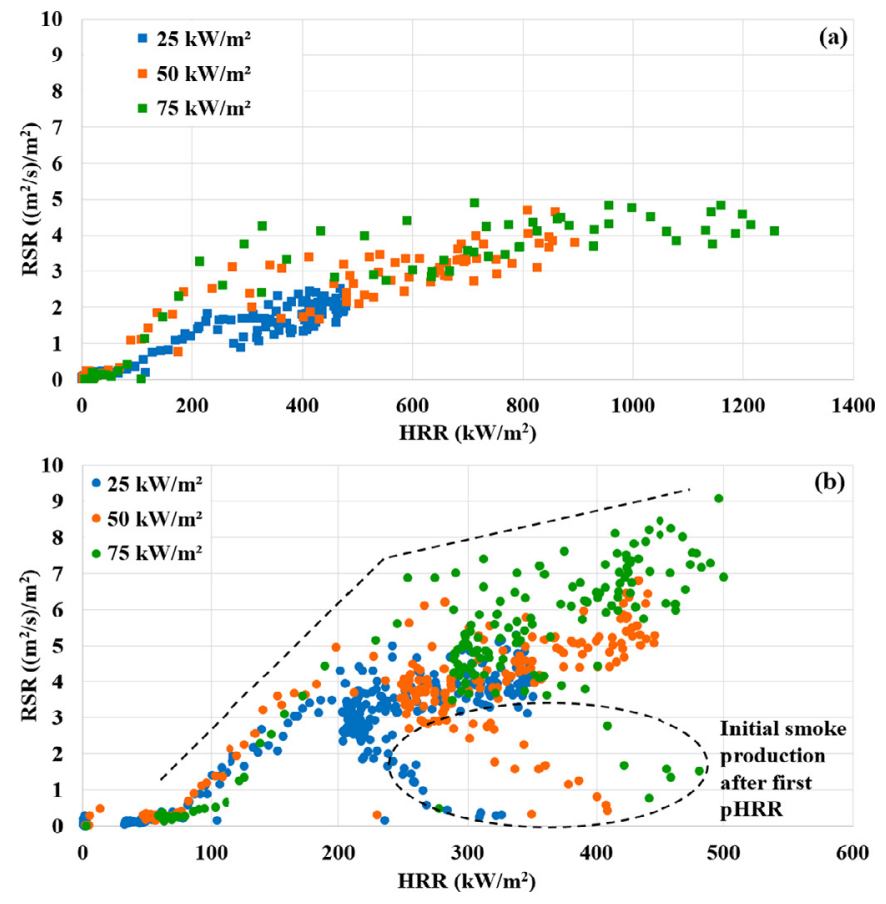

Fig. 14. RSR as function of HRR for (a) PMMA and (b) Kyowaglas. (For interpretation of the references to color in this figure legend, the reader is referred to the web version of this article.).

pHRR, RSR increases much faster with HRR. RSR is between 5-7 $\left(\mathrm{m}^{2} / \mathrm{s}\right) / \mathrm{m}^{2}$ for HRR equal to $400 \mathrm{~kW} / \mathrm{m}^{2}$. Then, smoke production is enhanced in Kyowaglas.

\subsection{Residue}

The main objective of this document is to achieve a characterization as complete as possible of Kyowaglas, in particular concerning its fire behavior. The first part of this paper described the material at room temperature before it was subjected to thermal stresses. Subsequently, a second part was devoted to the evaluation and the evolution of its thermal properties during combustion. This last part is then dedicated to the residue formation from the burning of Kyowaglas.

As mentioned above, while non-charring materials, as PMMA, burn completely without leaving a residue, Kyowaglas has a mass loss of around $70 \%$ as shown by TGA, PCFC measurements and cone tests. During the combustion of Kyowaglas, the material undergoes several changes in its physical state (see Fig. 15). Indeed, the material undergoes a transition from the solid state to a molten state (Fig. 15(a)), followed by a bubbling phenomenon (Fig. 15(b)) just before ignition (Fig. 15(c)). A residue thick layer begins to form as the combustion process continues (Fig. 15(d)). Before flameout, i.e. when flame starts to vanish, leaded beads appear on the surface (Fig. 15(e)). At the end of the test, the entire surface of the residue seems to be covered by small leaded beads of different sizes (Figs. 15(f) and 16).

In order to understand the origin of these beads, and given that they only appear towards the end of the test before flame out, three samples were analyzed by X-ray diffraction (XRD) (Fig. 17). The first sample (a) consists of Kyowaglas before burning. The second sample (b) consists of Kyowaglas residue which has undergone an interrupted cone test at the plateau level (for $\mathrm{t} \approx 220 \mathrm{~s}$ and at an irradiance level of $50 \mathrm{~kW} / \mathrm{m}^{2}$ ). At this stage, beads have not yet been observed but rather a yellowish residue in the center and black at the edges. The last sample (c) consists of Kyowaglas residue which has undergone a complete cone test. Fig. 18 shows 

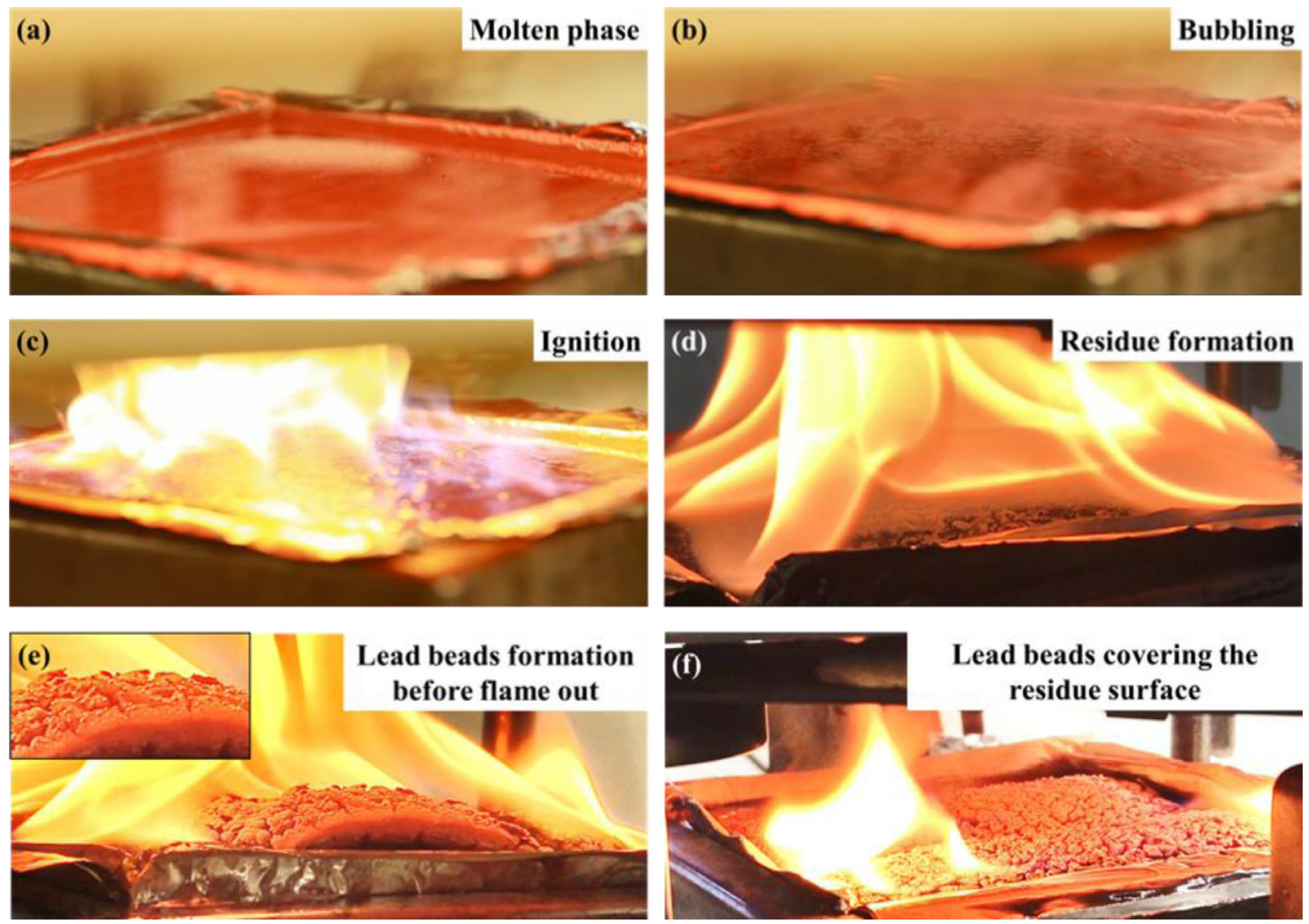

Fig. 15. Different burning stages of Kyowaglas.

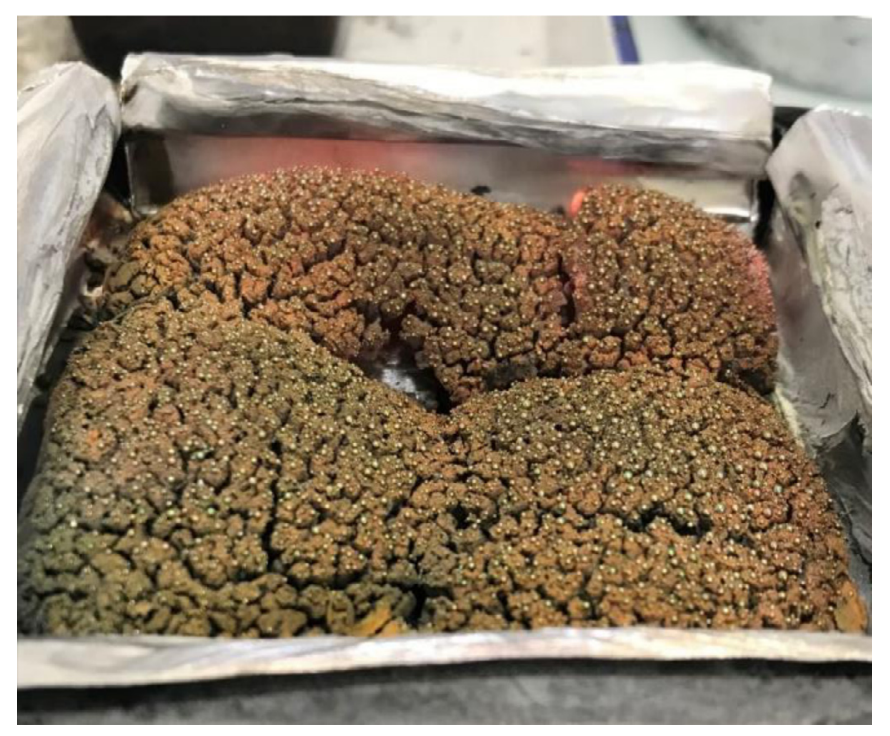

Fig. 16. Kyowaglas residue covered with leaded beads after a cone test. the XRD spectra obtained for each sample. On the first spectrum, no peak is observed evidencing that Kyowaglas is fully amorphous. On the second spectrum, two species appear: lead $(\mathrm{Pb})$ at $32^{\circ}, 36^{\circ}$, $52^{\circ}$ and $61^{\circ}[53,54]$, the remaining peaks are attributed to lead oxide $(\mathrm{PbO})$ with higher intensity $[55,56]$. On the last spectrum, the peaks of lead $(\mathrm{Pb})$ tend to disappear and only lead oxide is present while beads cover the whole surface.

Samples (b) and (c) are then analyzed using scanning electron microscope (SEM). An elementary analysis was also carried out in order to identify the elements present in these residues. For sample (b) three different zones of different colors are analyzed: yellow, grey and black zones. Figs. 19-21 present the SEM observations carried out on the three respective zones. Fig. 22 shows the microstructure of sample (c).

On Fig. 19 (yellow zone), plates of square geometric shape (yellow arrows) scattered in a spongy structure are observed. Elemental analysis of these structures shows that they consist of $19 \%$ at $\mathrm{Pb}$, $50.4 \%$ at carbon and $26 \%$ at oxygen. Regarding the grey area (Fig. 20), some filaments appear (red arrows); the geometric shapes observed in the yellow area no longer appear there. These filaments
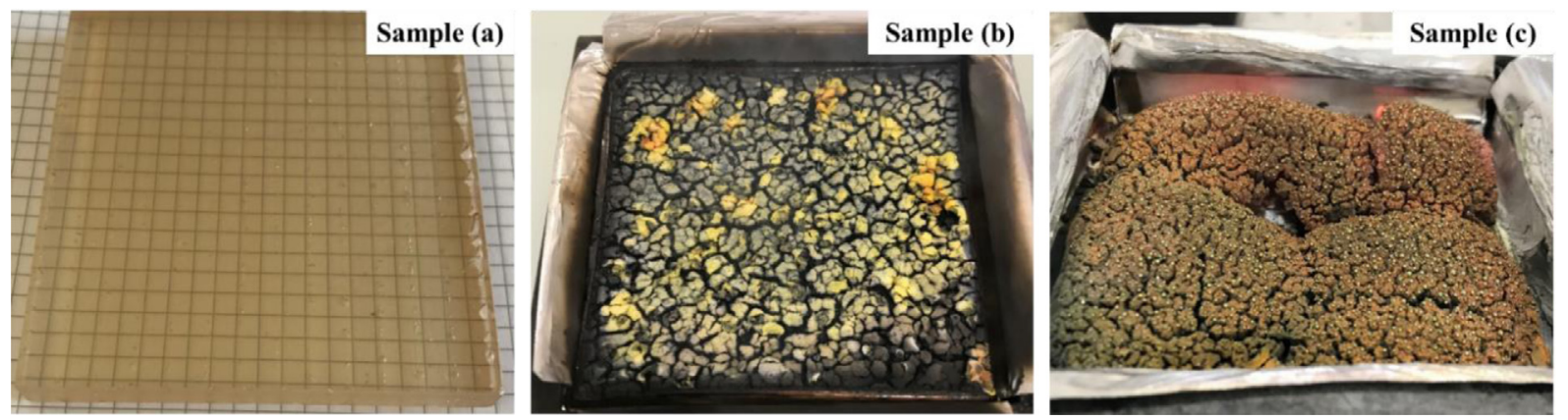

Fig. 17. Kyowaglas samples: (a) before cone calorimeter test, (b) after an interrupted cone calorimeter test at the plateau level and (c) after a complete cone calorimeter test. 


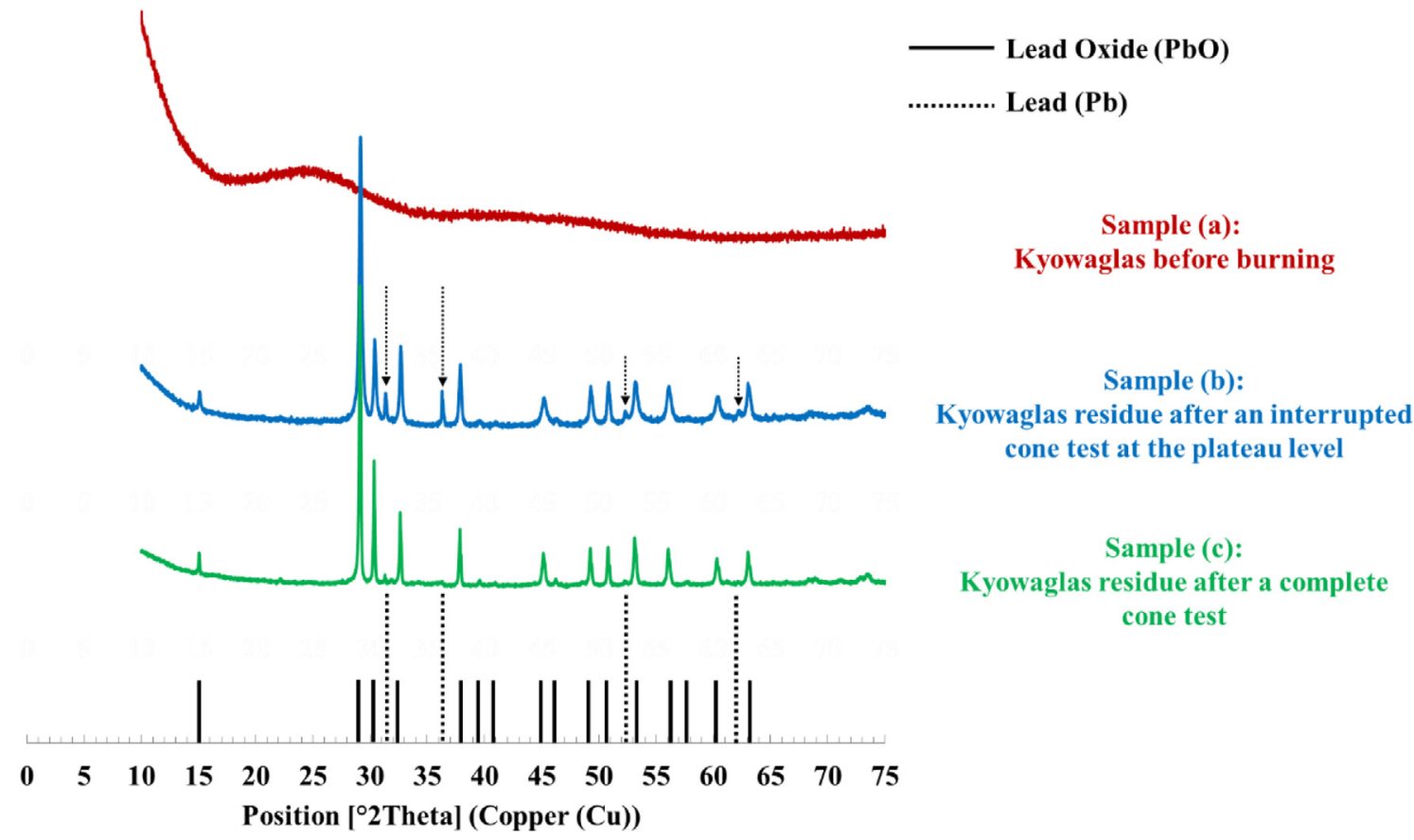

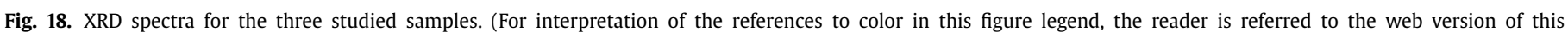
article.).
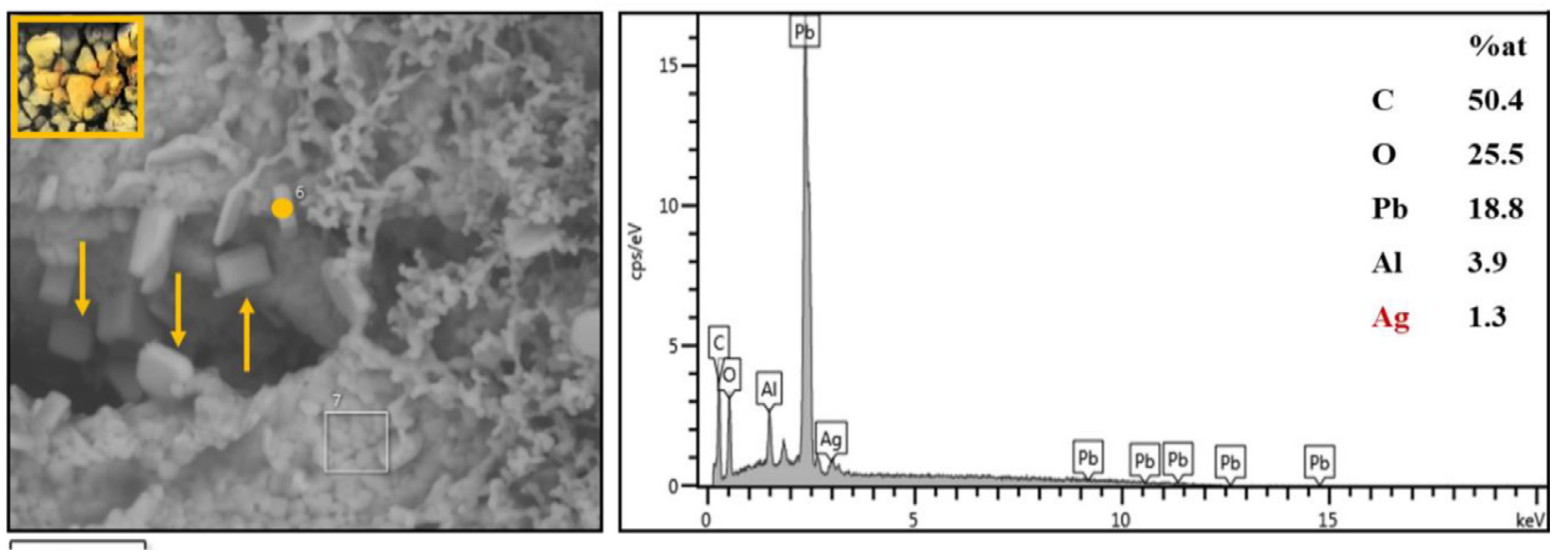

\section{$2.5 \mu \mathrm{m}$}

Fig. 19. Yellow zone analysis by SEM from sample (b).
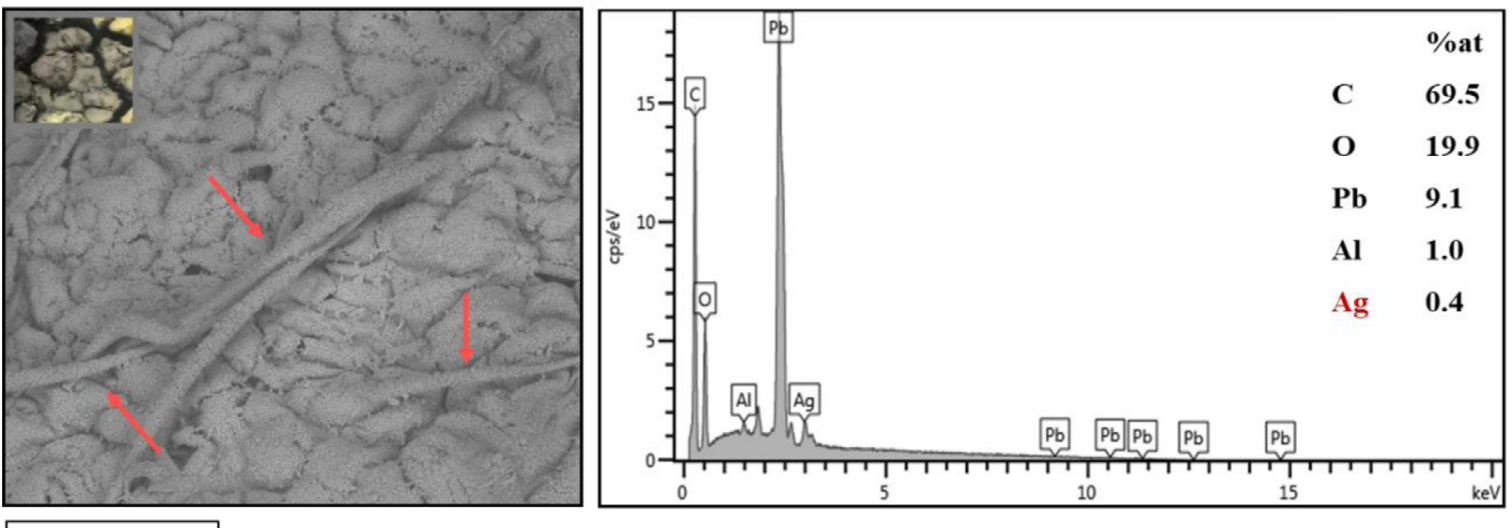

$200 \mu \mathrm{m}$

Fig. 20. Gray zone analysis by SEM from sample (b). 

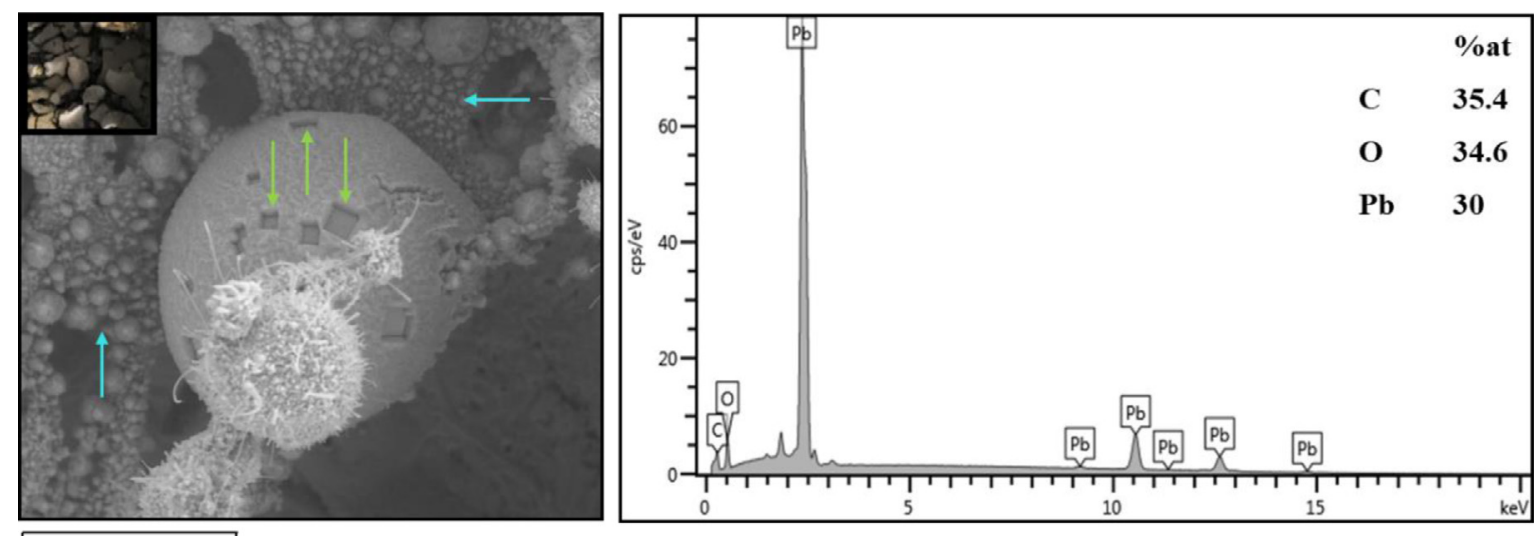

$50 \mu \mathrm{m}$

Fig. 21. Black zone analysis by SEM from sample (b).

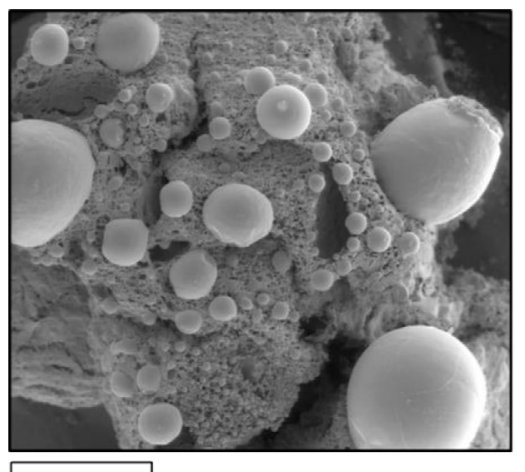

$1 \mathrm{~mm}$

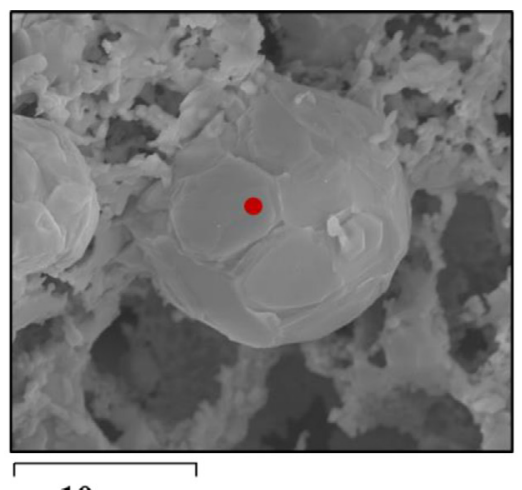

$10 \mu \mathrm{m}$

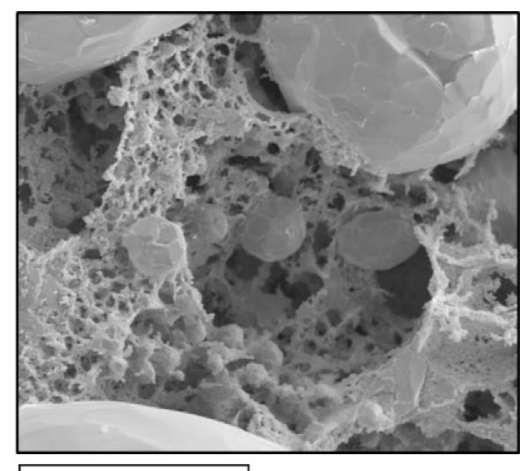

$50 \mu \mathrm{m}$

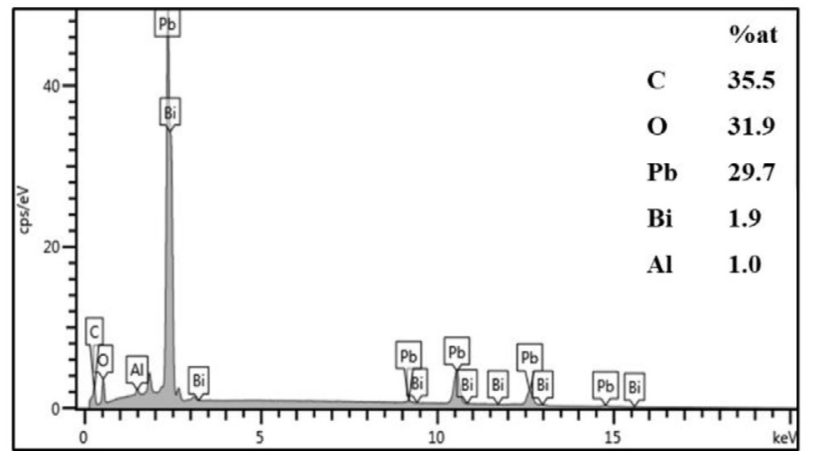

Fig. 22. SEM observations of different zones from sample (c) that has undergone a full cone test.

are made up of $10 \%$ at $\mathrm{Pb}, 70 \%$ at carbon and $20 \%$ at oxygen. Finally, the black area highlights the presence of leaded beads of different sizes. Indeed, Fig. 21 shows that the surface of the analyzed sample is covered with leaded beads (blue arrows). In addition, these beads appear to be formed from an arrangement of the square plates observed in the yellow area. Some of these plates are missing from the bead surface (green arrows). Elemental analysis of this zone shows that it is made up of $30 \%$ at $\mathrm{Pb}, 35 \%$ at carbon and $35 \%$ at oxygen.

With regard to sample (c), it should be reminded that it is a Kyowaglas residue obtained after a complete test with cone calorimeter, it highlights a significant presence of leaded beads distributed in a spongy structure. Fig. 22 shows different SEM observations of different zones from sample (c). The XRD spectrum of Fig. 18 shows that these beads are mainly composed of lead oxide (PbO).
Moreover, PCFC tests were carried out under different conditions (aerobic and/or anaerobic pyrolysis). Indeed, these tests can be divided into three categories. The first category consists of performing PCFC analysis on Kyowaglas under anaerobic pyrolysis conditions. The second category consists of performing PCFC analysis on Kyowaglas under aerobic pyrolysis conditions. The last category concerns PCFC analysis on Kyowaglas under anaerobic pyrolysis conditions and the resulting residue was subsequently tested with PCFC under conditions of aerobic pyrolysis. Fig. 23 shows the XRD spectra obtained for each sample. When Kyowaglas or its residue undergoes aerobic pyrolysis, there is no evidence of metallic lead $(\mathrm{Pb})$. In fact, the green and blue spectra only show the presence of lead oxide ( $\mathrm{PbO}$ ). However, when Kyowaglas undergoes anaerobic pyrolysis, four peaks are observed on the red spectrum which correspond to the metallic $\mathrm{Pb}$. 


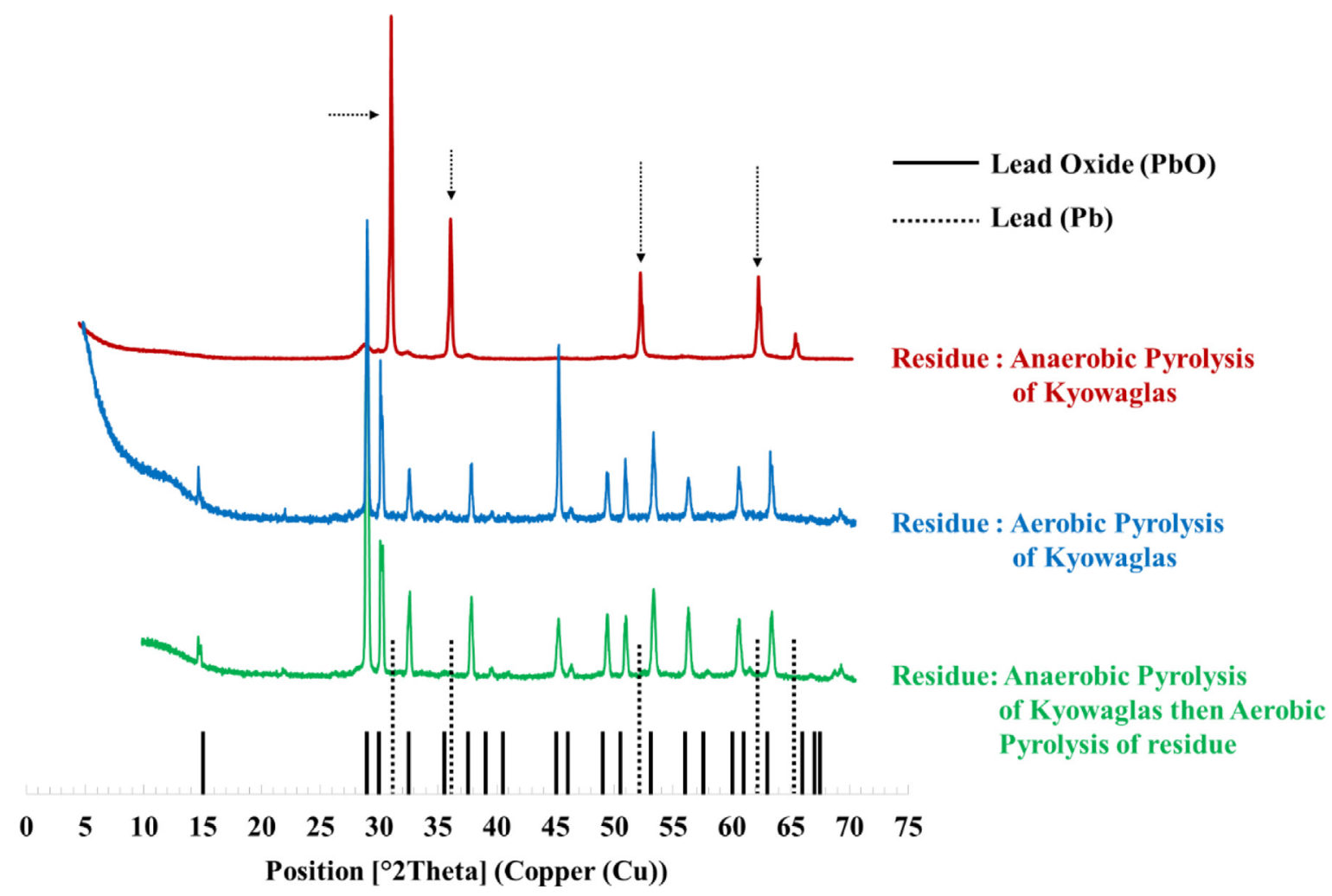

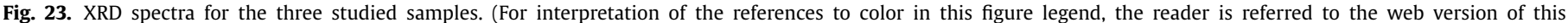
article.).

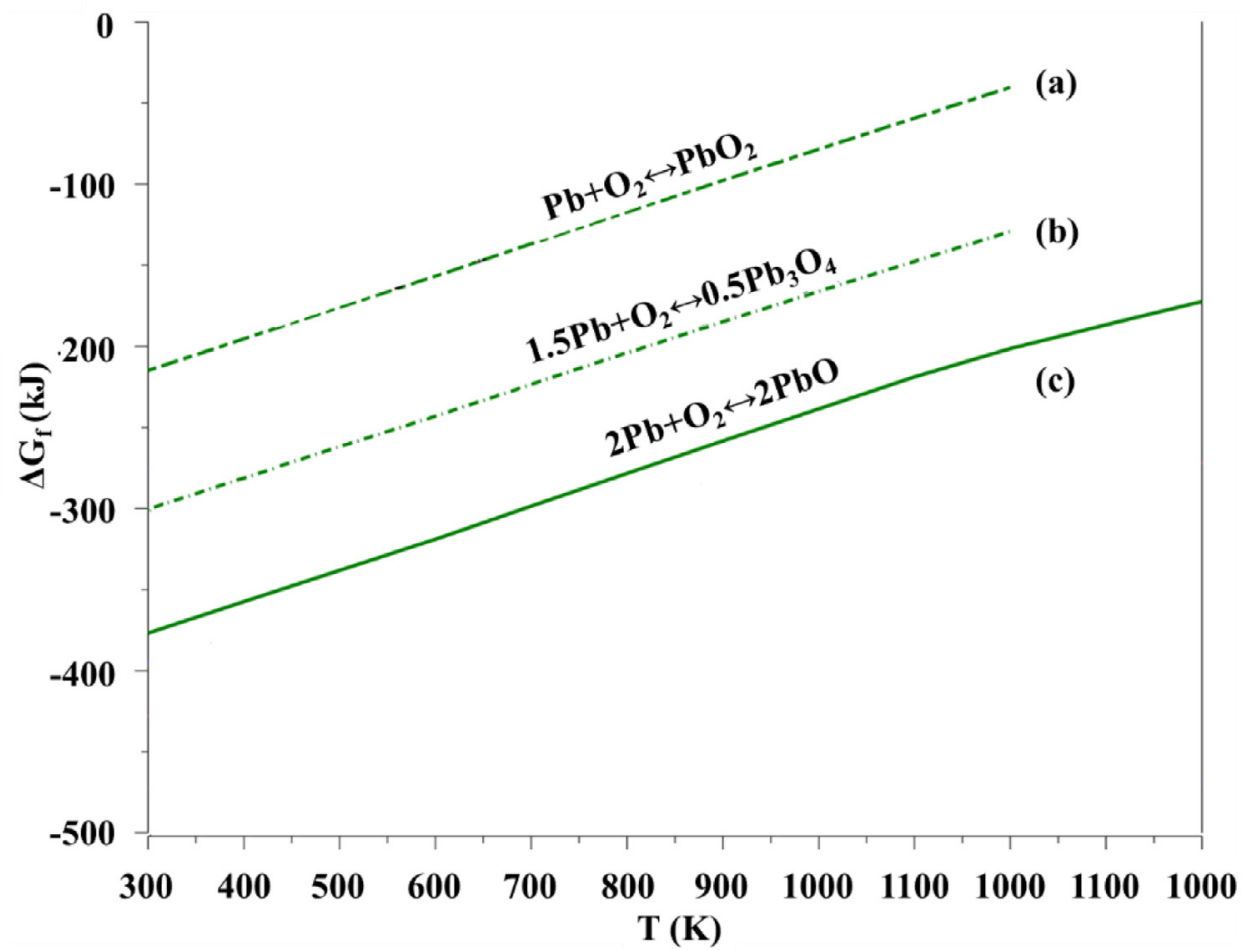

Fig. 24. Ellingham diagram of lead oxides at 1 bar. 
From the results obtained with PCFC, SEM and XRD, lead compounds, regardless of the form in which they exist in Kyowaglas, seem to change their morphology when they transform/decompose to $\mathrm{PbO}$. First, square plates are observed, which will then strongly aggregate to form microparticles preferentially assembled into spheres.

Furthermore, from these results, the oxidation of lead to form $\mathrm{PbO}$ seems to occur only when the temperature drops and in the presence of oxygen. Indeed, the XRD analysis shows the presence of $\mathrm{PbO}$ :

- At the edges of the sample having undergone an interrupted cone calorimeter test (Fig. 21 (sample b)).

- Over the entire residue surface of the sample having undergone a complete cone calorimeter test (Fig. 18 (sample c)).

- In the residue of the sample which has undergone aerobic pyrolysis with PCFC (Fig. 23 - blue curve).

Metallic lead is only detected in certain areas of the residue from the interrupted cone test (probably the yellow area) and in the residue of the sample that has undergone anaerobic pyrolysis with PCFC.

This can be explained by the Ellingham diagram. The latter makes it possible to foresee the temperature dependence of the stability of compounds and to predict the equilibria between a metal and its oxides as a function of temperature [57]. The Ellingham diagram plots the Gibbs free energy $(\Delta G)$ for oxidation reactions as a function of temperature. The $\Delta \mathrm{G}$ of a reaction evaluates the thermodynamic driving force that makes a reaction occur. If $\Delta G$ is negative, the reaction occurs spontaneously. If $\Delta G$ is positive, the reaction cannot occur spontaneously without external inputs (like heat). Most commonly known lead oxide pairs were plotted in Fig. 24. This diagram offers various features. Among these features, we are interested in two in particular. Feature (1) states that the lower the position of a metal's line in the Ellingham diagram, the greater is the stability of its oxide [58]. Indeed, when the reaction's line is closer to the top of the diagram $(\Delta G \rightarrow 0)$, the metal's oxides are unstable, these reactions concern mainly "noble" metals, like platinum and gold. As the reaction's line moves down toward the bottom of the diagram, metals become progressively more reactive and their oxides become more stable. Feature (2) assumes that the stability of metallic oxides decreases with increase in temperature because compounds become less stable as their free energy gets close to zero [59].

From the reactions presented in Fig. 24, reaction (c) is to be the most favorable (feature (1)), since its free energy value is the most negative of all. From this plot, and the XRD spectra presented above, it is clear that PbO is the only lead oxide that could be formed. It is reasonable to think that regions where $\mathrm{PbO}$ is detected are richer in Oxygen than other zones. Such Oxygen is likely to combine with $\mathrm{Pb}$ in Kyowaglas to form $\mathrm{PbO}$.

However, according to feature (2), PbO is less stable thus does not form at high temperatures. This could explain the appearance of the $\mathrm{PbO}$ beads during the last moments of the test, just before flameout when the temperature decreases and when a greater amount of oxygen is available.

\section{Conclusions}

In this paper, the fire behavior of pure PMMA and Kyowaglas, composed of 70\% PMMA and 30\% leaded compounds, is evaluated.

TGA analyzes under inert gas show that the decomposition of Kyowaglas takes place in two stages and only one for PMMA. This double decomposition of Kyowaglas is verified with PCFC under anaerobic pyrolysis. The final mass obtained being equal to the weight percentage of lead in the Kyowaglas. This means that leadcompounds remain in the condensed phase.
Cone calorimetry results highlight a lower flammability for Kyowaglas compared to PMMA. Indeed, the rate of heat release during combustion tends to decrease when lead is incorporated (Kyowaglas). In contrast, the total smoke given off during combustion increases strongly when lead is incorporated. Indeed, the value of TSR is practically doubled for Kyowaglas. The mass loss curves recorded during the cone calorimeter tests show a sort of stabilizing effect of lead, and the final quantities of residues obtained correspond well to the mass of lead species incorporated in the Kyowaglas. The low flammability observed in the case of Kyowaglas is probably due to the barrier effect which, on the one hand, limits the fluxes between the flame and the condensed phase and on the other hand allows a higher heating of the surface.

As a non-charring material, PMMA burns completely without leaving a residue. On the other hand, Kyowaglas has a mass loss of around 70\%. SEM and XRD analyses on the Kyowaglas residue showed that metallic lead forms as the Kyowaglas burns. However, this metallic lead seems to oxidize with the ambient oxygen to form $\mathrm{PbO}$ beads which cover the entire surface of the residue towards the end of the cone tests, just before flameout, when the temperature drops and oxygen availability increases.

\section{Declaration of Competing Interest}

The authors declare that they have no known competing financial interests or personal relationships that could have appeared to influence the work reported in this paper.

\section{CRediT authorship contribution statement}

H. Mastori: Project administration, Methodology, Data curtion, Writing - original draft. R. Sonnier: Supervision, Writing - review \& editing. L. Ferry: Supervision, Writing - review \& editing. M. Coutin: Supervision, Writing - review \& editing.

\section{Acknowledgement}

The authors are grateful for the cooperation of the Secretariat of Nuclear Regulation Authority (NRA, Japan) for this work carried out within the framework of the FIGARO program devoted to the study of glove box fires and the suspension of radioactive aerosols. The authors also wish to express their gratitude to M. Loïc Dumazert and M. Benjamin Gallard from IMT - Mines Ales for their support.

\section{Supplementary materials}

Supplementary material associated with this article can be found, in the online version, at doi:10.1016/j.polymdegradstab.2021. 109618.

\section{References}

[1] M. Coutin, L. Audouin, Glove box fire behaviour in free atmosphere, SMiRT 24, 15th Int. Post-Conference Semin. Fire Saf. Nucl. Power Plants Install., 2017.

[2] A.M. El-Khatib, M.I. Abbas, M.A. Elzaher, M.S. Badawi, M.T. Alabsy, G.A. Alharshan, D.A. Aloraini, Gamma Attenuation Coefficients of Nano Cadmium Oxide/High density Polyethylene Composites, Report No. 16012, 2019. https://doi.org/10.1038/s41598-019-52220-7.

[3] R.E. Lyon, R. Walters, A Microscale Combustion Calorimeter, Report No. DOT/FAA/AR-01/117, 2002.

[4] R.E. Lyon, R.N. Walters, Pyrolysis combustion flow calorimetry, J. Anal. Appl. Pyrol. 71 (2004) 27-46, doi:10.1016/S0165-2370(03)00096-2.

[5] American Society for Testing and Materials (ASTM)ASTM D7309-11, Standard Test Method for Determining Flammability Characteristics of Plastics and Other Solid Materials Using Microscale Combustion Calorimetry, ASTM, West Conshohocken, PA, USA, 2011.

[6] Babrauskas, V. (1982), Development of the Cone Calorimeter: A Bench-Scale Heat Release Rate Apparatus Based on Oxygen Consumption., NIST Interagency/Internal Report (NISTIR), National Institute of Standards and Technology, Gaithersburg, MD (Accessed May 25, 2021) 
[7] V. Babrauskas, Development of the cone calorimeter - a bench-scale heat release rate apparatus based on oxygen consumption, Fire Mater. 8 (1984) 81-95, doi:10.1002/fam.810080206.

[8] C. Huggett, Estimation of rate of heat release by means of oxygen consumption measurements, Fire Mater. 4 (1980) 61-65, doi:10.1002/fam.810040202.

[9] M.L. Janssens, Measuring rate of heat release by oxygen consumption, Fire Technol. 27 (1991) 234-249, doi:10.1007/BF01038449.

[10] ISO 5660-1:2002, Reaction-to-fire tests - heat release, smoke production and mass loss rate - part 1 : heat release rate (cone calorimeter method), n.d.

[11] ISO 5660-2:2002, Reaction-to-fire tests - heat release, smoke production and mass loss rate - part 2: smoke production rate (dynamic measurement), n.d.

[12] ISO 5660-3:2012, Reaction-to-fire tests - heat release, smoke production and mass loss rate - part 3: guidance on measurement, n.d.

[13] American Society for Testing and Materials (ASTM)ASTM E1354-17, Standard Test Method for Heat and Visible Smoke Release Rates for Materials and Products Using an Oxygen Consumption Calorimeter, ASTM, West Conshohocken, PA, USA, 2017.

[14] J.F. Maguire, Custom mobile, (1991). https://www.customsmobile.com/rulings/ docview?doc_id=HQ087722\&highlight=HQ087722\# (accessed July 21, 2020).

[15] R.E. Lyon, M.L. Janssens, Polymer flammability, in: Encyclopedia of Polymer Sci- ence and Technology, Wiley, 2015, pp. 1-70, doi: 10.1002/0471440264.pst135. pub2.

[16] T. Fateh, F. Richard, T. Rogaume, P. Joseph, Experimental and modelling studies on the kinetics and mechanisms of thermal degradation of polymethyl methacrylate in nitrogen and air, J. Anal. Appl. Pyrol. 120 (2016) 423-433, doi:10.1016/j.jaap.2016.06.014

[17] M. Kumar, S. Arun, P. Upadhyaya, G. Pugazhenthi, Properties of PMMA/clay nanocomposites prepared using various compatibilizers, Int. J. Mech. Mater. Eng. 10 (2015) 7, doi:10.1186/s40712-015-0035-X.

[18] F. Laoutid, R. Sonnier, D. Francois, L. Bonnaud, N. Cinausero, J.-M.L.M.L. Cuesta, P. Dubois, Effect of magnesium dihydroxide nanoparticles on thermal degrada- tion and flame resistance of PMMA nanocomposites, Polym. Adv. Technol. 22 (2011) 1713-1719, doi:10.1002/pat.1661.

[19] T.R. Crompton, Plastics Reinforcement and Industrial Applications Cromptom, CRC Press, 2015.

[20] V. Harish, N. Nagaiah, Thermal degradation of lead monoxide filled polymer composite radiation shields, AIP Conf. Proc. 1349 (2011) 89-90, doi:10.1063/1. 3605751.

[21] R.E. Lyon, R.N. Walters, S.I. Stoliarov, Screening flame retardants for plastics using microscale combustion calorimetry, Polym. Eng. Sci. 47 (2007) 1501-1510, doi: $10.1002 /$ pen.20871

[22] A. Tewarson, Generation of heat and chemical compounds in fires, in: SFPE Handbook of Fire Protection Engineering, National Fire Protection Association, Inc., One Batterymarch Park Quincy, Massachusetts 02269, 2002, pp. 3.82-3.161. Quincy, MA, USA.

[23] B. Schartel, M. Bartholmai, U. Knoll, Some comments on the use of cone calorimeter data, Polym. Degrad. Stab. 88 (2005) 540-547, doi:10.1016/j. polymdegradstab.2004.12.016.

[24] J. Luche, T. Rogaume, F. Richard, E. Guillaume, Characterization of thermal properties and analysis of combustion behavior of PMMA in a cone calorimeter, Fire Saf. J. 46 (2011) 451-461, doi:10.1016/j.firesaf.2011.07.005.

[25] G. Linteris, L. Gewuerz, K. Mcgrattan, G. Forney, Modeling solid sample buming, Fire Saf. Sci. 8 (2005) 625-636, doi:10.3801/IAFSS.FSS.8-625.

[26] B. Schartel, T.R. Hull, Development of fire-retarded materials-interpretation of cone calorimeter data, Fire Mater. 31 (2007) 327-354, doi:10.1002/fam.949

[27] M. Suzanne, A. Ramani, S. Ukleja, M. McKee, J. Zhang, M. Delichatsios, D. Bakirtzis, Experimental and numerical study of thermal stability and fire performance of brominated and halogen-free flame retardants in glass-fibre reinforced poly(butylene terephthalate), Fire Saf. Sci. 11 (2014) 832-845, doi:10. 3801/IAFSS.FSS.11-832.

[28] L. Shi, M.Y.L. Chew, Fire behaviors of polymers under autoignition conditions in a cone calorimeter, Fire Saf. J. 61 (2013) 243-253, doi:10.1016/j.firesaf.2013. 09.021.

[29] L. Tsantaridis, Reaction to Fire Performance of Wood and other Building Products - Cone CALORIMETER Results and Analysis, Reaction to Fire Performance of Wood and other Building Products - Cone CALORIMETER Results and Analysis, KTH Royal Institute of Technology, Stockholm, 2003.

[30] S. Ullah, F. Ahmad, A.M.M. Shariff, M.A.A. Bustam, Synergistic effects of kaolin clay on intumescent fire retardant coating composition for fire protection of structural steel substrate, Polym. Degrad. Stab. 110 (2014) 91-103, doi:10.1016/ j.polymdegradstab.2014.08.017.

[31] R.N. Rothon, P.R. Hornsby, Flame retardant effects of magnesium hydroxide, Polym. Degrad Stab 54 (1996) 383-385, doi:10.1016/S0141-3910(96)00067-5.

[32] A.T. Grenier, N.A. Dembsey, J.R. Barnett, Fire characteristics of cored composite materials for marine use, Fire Saf. J. 30 (1998) 137-159, doi:10.1016/ S0379-7112(97)00059-3.
[33] M.A. Delichatsios, Piloted ignition times, critical heat fluxes and mass loss rates at reduced oxygen atmospheres, Fire Saf. J. 40 (2005) 197-212, doi:10.1016/j. firesaf.2004.11.005.

[34] W. An, L. Jiang, J. Sun, K.M. Liew, Correlation analysis of sample thickness, heat flux, and cone calorimetry test data of polystyrene foam, J. Therm. Anal. Calorim. 119 (2015) 229-238, doi:10.1007/s10973-014-4165-9.

[35] L. Shi, M.Y.L. Chew, Experimental study of woods under external heat flux by autoignition, J. Therm. Anal. Calorim. 111 (2013) 1399-1407, doi:10.1007/ s10973-012-2489-X.

[36] W.R. Zeng S.F. Li, W.K. Chow, Preliminary studies on burning behavior of polymethylmethacrylate (PMMA), J. Fire Sci. 20 (2002) 297-317, doi:10.1177/ 073490402762574749.

[37] N.A. Dembsey, D.J. Jacoby, Evaluation of common ignition models for use with marine cored composites, Fire Mater. 24 (2000) 91-100, doi:10.1002 1099-1018(200003/04)24:2 91::AID-FAM725<3.0.CO;2-0.

[38] J.G. Quintiere, A theoretical basis for flammability properties, Fire Mater. 30 (2006) 175-214, doi:10.1002/fam.905.

[39] D. Quang Dao, J. Luche, F. Richard, T. Rogaume, C. Bourhy-Weber, S. Ruban, Determination of characteristic parameters for the thermal decomposition of epoxy resin/carbon fibre composites in cone calorimeter, Int. J. Hydrogen Energy 38 (2013) 8167-8178, doi:10.1016/j.ijhydene.2012.05.116.

[40] N. Hernández, A. Fuentes, P. Reszka, A.C. Fernández-Pello, Piloted ignition delay times on optically thin PMMA cylinders, Proc. Combust. Inst. 37 (2019) 39934000, doi:10.1016/j.proci.2018.06.053.

[41] R. Gardon, A review of radiant heat transfer in glass, J. Am. Ceram. Soc. 44 (1961) 305-312, doi:10.1111/j.1151-2916.1961.tb15914.x.

[42] F. Jiang, J.L. de Ris, M.M. Khan, Absorption of thermal energy in PMMA by in-depth radiation, Fire Saf. J. 44 (2009) 106-112, doi:10.1016/j.firesaf.2008.04. 004.

[43] G. Linteris, M. Zammarano, B. Wilthan, L. Hanssen, Absorption and reflection of infrared radiation by polymers in fire-like environments, Fire Mater. 36 (2012) 537-553, doi:10.1002/fam.1113.

[44] B.T. Rhodes, J.G. Quintiere, Burning rate and flame heat flux for PMMA in a cone calorimeter, Fire Saf. J. 26 (1996) 221-240, doi:10.1016/S0379-7112(96) 00025-2.

[45] D. Hopkins, J.G. Quintiere, Material fire properties and predictions for thermoplastics, Fire Saf. J. 26 (1996) 241-268, doi:10.1016/S0379-7112(96)00033-1.

[46] D. Drysdale, An Introduction to Fire Dynamics, John Wiley \& Sons, Ltd, Chichester, UK, 2011, doi:10.1002/9781119975465.

[47] J.G. Quintiere, Fundamentals of Fire Phenomena, John Wiley \& Sons, Ltd, Chichester, UK, 2006, doi:10.1002/0470091150.

[48] T.-H.H. Tsai, M.-J.J. Li, I.-Y.Y. Shih, R. Jih, S.-C.C. Wong, Experimental and numerical study of autoignition and pilot ignition of PMMA plates in a cone calorimeter, Combust. Flame. 124 (2001) 466-480, doi:10.1016/S0010-2180(00) 00219-4.

[49] ISO5660, Reaction to fire tests-heat release, smoke production and mass loss rate-Part 1 Heat release rate (cone calorimeter method), 2002.

[50] B.T. Rhodes, Burning rate and flame heat flux for PMMA in the cone calorimeter, 1994.

[51] S. Agrawal, A. Atreya, Wind-aided flame spread over an unsteadily vaporizing solid, Symp. Combust. 24 (1992) 1685-1693, doi:10.1016/S0082-0784(06) 80197-9.

[52] R. Sonnier, H. Vahabi, C. Chivas-Joly, New insights into the investigation of smoke production using a cone calorimeter, Fire Technol. 55 (2019) 853-873, doi:10.1007/s10694-018-0806-z.

[53] T. Theivasanthi, M. Alagar, Konjac bio-molecules assisted - rod /spherical shaped lead nano powder synthesized by electrolytic process and its characterization studies, Nano Biomed. Eng. 5 (2013), doi:10.5101/nbe.v5i1.p10-19.

[54] F. Gontad, A. Lorusso, A. Klini, A. Loufardaki, M. Panareo, C. Fotakis, A. Perrone, Picosecond and subpicosecond pulsed laser deposition of $\mathrm{Pb}$ thin films, Phys. Rev. Spec. Top. - Accel. Beams. 16 (2013) 093401, doi:10.1103/PhysRevSTAB.16. 093401.

[55] S. Elawam, W. Morsi, H. Abou-Shady, O. Guirguis, Characterizations of betalead oxide "massicot" nano-particles, Br. J. Appl. Sci. Technol. 17 (2016), doi:10. 9734/bjast/2016/28143.

[56] J.M.P. Almeida, G.F.B. Almeida, A.C. Hernandes, C.R. Mendonça, Architecture of lead oxide microcrystals in glass: a laser and etching based method, CrystEngComm 18 (2016), doi:10.1039/c6ce01255h.

[57] M. Hasegawa, Ellingham diagram, in: Treatise on Process Metallurgy, Elsevier, 2014, pp. 507-516, doi:10.1016/B978-0-08-096986-2.00032-1.

[58] J.H.E. Jeffes, Ellingham diagrams, in: Encyclopedia of Materials: Science and Technology, Elsevier, 2001, pp. 2751-2753, doi:10.1016/B0-08-043152-6/ 00490-3.

[59] E. Cheremisina, J. Schenk, Chromium stability in steel slags, Steel Res. Int. 88 (2017) 1700206, doi:10.1002/srin.201700206. 